\title{
12 Symsagittifera roscoffensis as a Model in Biology
}

\author{
Pedro Martinez, Volker Hartenstein, Brenda Gavilán, \\ Simon G. Sprecher and Xavier Bailly
}

In memoriam of our friend and colleague Heinrich Reichert.

\section{CONTENTS}

12.1 Introduction

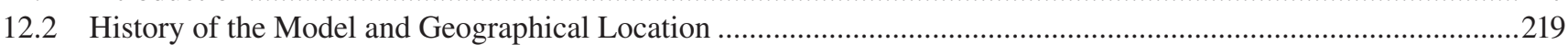

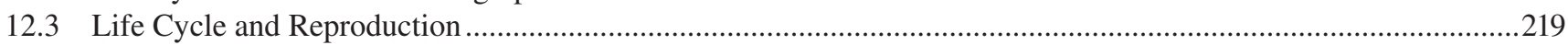

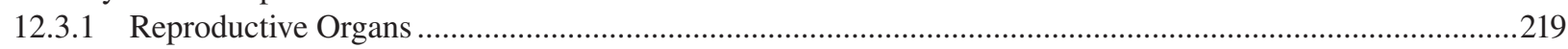

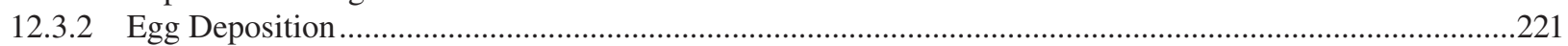

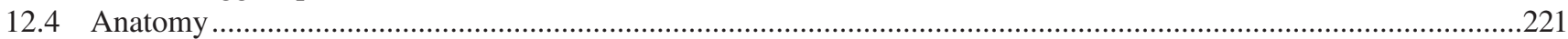

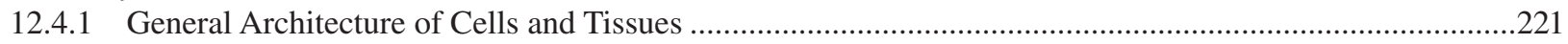

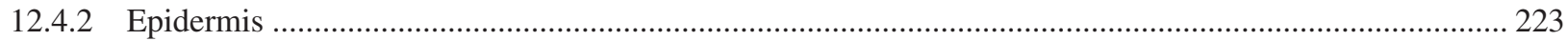

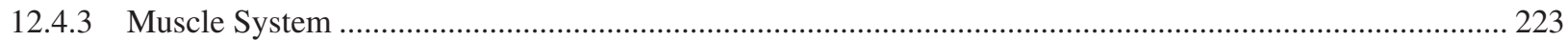

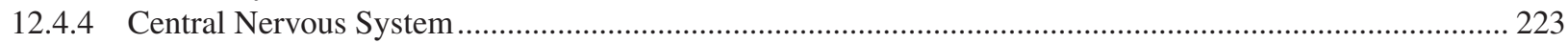

12.4.5 Peripheral Nervous System and Sensory Receptors............................................................................ 225

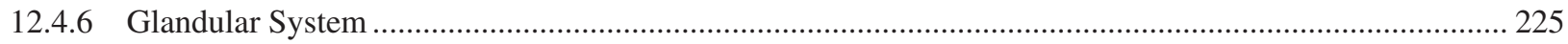

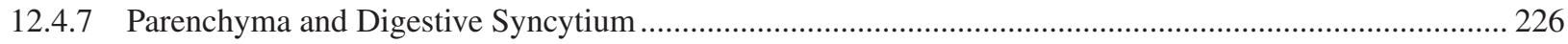

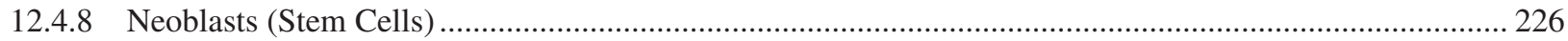

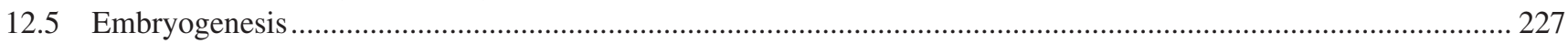

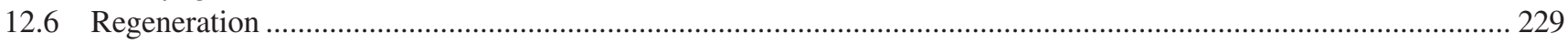

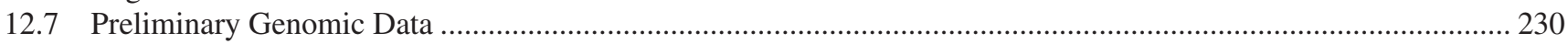

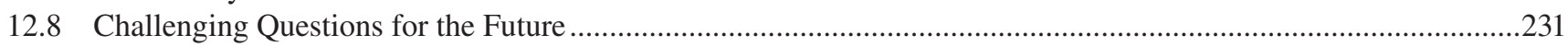

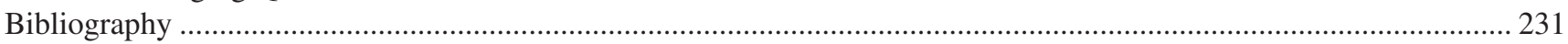

\subsection{INTRODUCTION}

Lynn Margulis (1938-2011), the iconoclastic scientist who shed light on biological evolutionary mechanisms that have driven the emergence of eukaryotic cell complexity by sequences of mergers of different type of bacteria, often referred in her works to marine "sunbathing green worms" from beaches of Brittany, France (Margulis 1998). She exemplified the sometimes uncritically accepted serial endosymbiotic theory (Sagan 1967) by pointing at this photosynthetic animal, a sustainable assemblage combining a marine flatworm and a dense population of photosynthetically active green microalgae localized under its epidermis (Figure 12.1a, b). From a rhetorical standpoint, the use of an oxymoron to describe a biological system (photosynthesis is not expected to be a property of metazoan tissues) can be a crucial educational and pedagogical lever. It provides a strong illustration for introducing and promoting the holobiont paradigm, which conceives of all living beings as complex assemblages formed by different organisms that constantly communicate.

We present herein descriptions related to the history, biology and ecology of Symsagittifera roscoffensis which have led to the emergence of this metazoan as a marine model organism, a photosymbiotic flatworm living together with in hospite green microalgae in its tissues, giving the typically green color to the animals (hence the name "mint-sauce worm"). Symsagittifera roscoffensis became attractive for research because gravid specimens can be found abundantly on specific beaches along the Atlantic coast, and all stages of development are easily accessible in the lab. Recent zootechnical advances allow for completing the life cycle in captivity; this includes deseasonalization (bypassing the annual reproductive diapause) but above all conserving colonies for months, with very low mortality and high reproduction rate. Culture standardization is critical to provide wide access to $S$. roscoffensis as a system exhibiting various biological properties, from brain regeneration to photosymbiosis. 

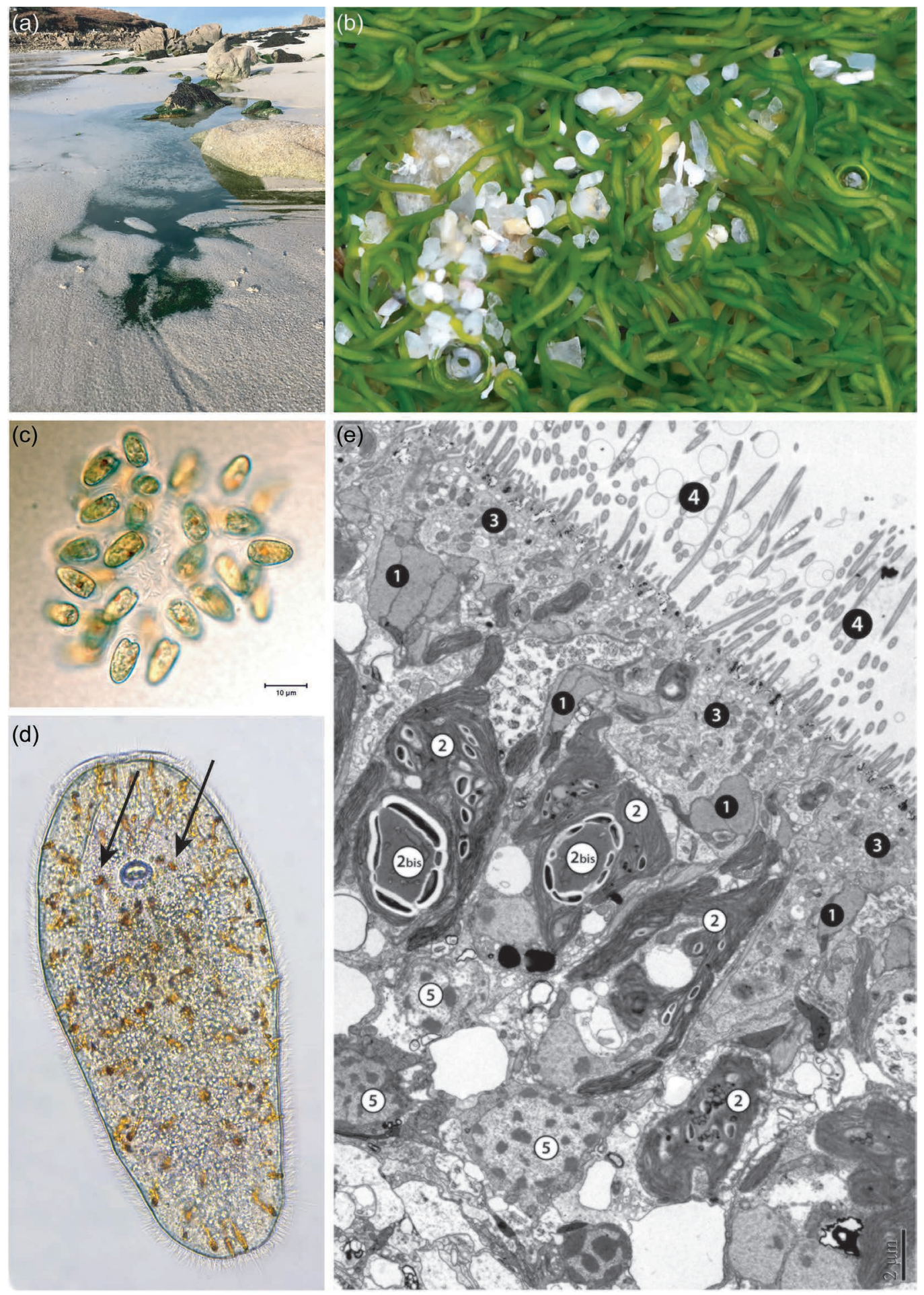

(d)

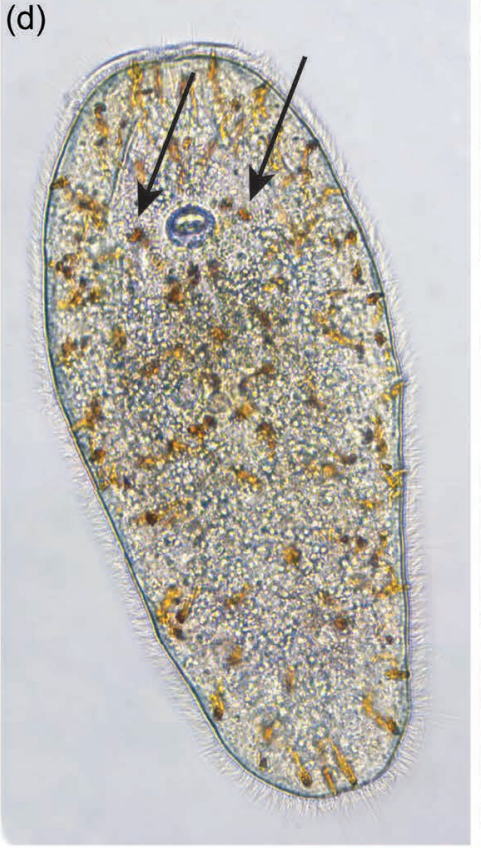

FIGURE 12.1 S. roscoffensis biotope and its photosymbiont. (a) At low tide, millions of S. roscoffensis specimens emerge from the sand and aggregate in puddles or gentle flow streams until the next high tide. The whole colony appears as a green mat. (b) Enlarged view of (a) showing high density of $S$. roscoffensis. Each adult flatworm is about 3 millimeters long. The white filaments in the middle of the body are oocytes (gravid animals). (c) Free-living algae Tetraselmis convolutae: The difference of phenotype between the in hospite microalgae and the free-living relatives are mainly noticeable by the absence of a cell wall (and the flagella) resulting from its ingestion in the animal tissues. (d) A freshly hatched, transparent juvenile of about 250 to 300 micrometers long. The brownish cells homogeneously spread along the body are rhabdites, rod-shaped, epidermal, mucus-secreting bodies (Smith et al. 1982). Two black arrows point to the photoreceptors at both sides of the statocyst (gravity sensor). (e) A transmission electron microscopy picture of the epidermal and subepidermal layers of the animal. Above the muscle fibers, organized as a net (1), lay the epidermal ciliated cells (3 and 4). The photosymbiont algae (2) are localized beneath the muscle layer (the closest position within the parenchyma to sense the light). Most of the microalgae cellular space is occupied by the thylakoids (lamellar-like structure = dedicated to photon harvesting) with a characteristic central structure, the pyrenoid (2bis), surrounded by the white halo (a sign of starch synthesis). Microalgae are in close contact with animal cells (5). 


\subsection{HISTORY OF THE MODEL AND GEOGRAPHICAL LOCATION}

In the first publications, addressing the nature and origin of the "green bodies" conferring the animals' green color (Geddes 1879) and the intriguing simplicity of the body plan (Delage 1886), S. roscoffensis was first mistakenly referred to as Convoluta schultzii, a phenotypically similar species previously described from the Adriatic Sea. An accurate taxonomic description was performed by Ludwig von Graff, hosted in a marine biological laboratory outpost on the coasts of North Brittany, France, now called the Station Biologique de Roscoff. As a tribute to the spirit of hospitality associated with facilities provided for exploration and experimentation of the surrounding marine environment, von Graff named this species Convoluta roscoffensis (von Graff 1891). Since then, colonies of billions of individuals have been observed on sandy beaches, distributed all along the Atlantic coast of Europe, from Wales to Portugal. The in hospite enigmatic green cells in the original description were first described as chloroplasts vertically transferred as colorless leucoplasts (Graff and Haberlandt 1891). They were later isolated and identified as free-living quadri-flagellate green microalgae (Gamble and Keeble 1904), known today as Tetraselmis convolutae (Figure 12.1c), and formerly named Platymonas convolutae (Parke and Manton 1967). Revisited with molecular taxonomy tools (Kostenko and Mamkaev 1990), Convoluta roscoffensis was renamed Symsagittifera roscoffensis. Initially positioned inside the Platyhelminthes phylum as an acoel turbellarian, this species is now a member of the phylum Xenacoelomorpha (Philippe et al. 2011), whose critically - and currently unresolved-phylogenetic position in the animal tree of life is discussed further.

$S$. roscoffensis has initially been used in a wide range of studies as a model for deciphering the mechanisms of the setting up, specificity and trophic relationship of this photosymbiosis in the intertidal zone. Gravid adult $S$. roscoffensis lay a translucid cocoon with embryos that develop to the aposymbiotic juvenile stage within four to five days (Figure 12.1d). If juveniles, once outside the cocoon, fail to ingest the microalgae, they do not survive to maturity, indicating that this association is obligate, with the animal feeding on photosynthates transferred from the photosymbiont (Keeble 1907). The aposymbiotic $S$. roscoffensis juvenile specifically incorporates but do not digest some Tetraselmis convolutae. These microalgae, in comparison to other closely related species (T. chui/subcoriformis/suecica), exhibit a special mode of division, whereby daughter cells stay in pairs in the parent theca for a much longer period, a factor favoring ingestion by the "benthic" juvenile acoel. The in hospite microalgae are taken up into the digestive syncytium and undergo morphological alterations compared to the free-living state, losing their theca (cell wall), eyespot and flagella but retaining an imposing chloroplast and a specific shape with fingerlike processes (Oshman 1966; Figure 12.1e). This suggests that microalgal cellular processes leading to high levels of energy consumption are drastically reduced in favor of increasing photosynthesis and production of organic molecules. Mannitol and starch (visible as grains in the chloroplast-Figure 12.1e) are the major carbohydrates in both free-living and in hospite microalgae (Gooday 1970). The photosynthetically fixed carbon, moving from the microalgae to the animal are mostly amino acids (Muscatine 1974). The nitrogen source for the in hospite algae (i.e. for amino acid synthesis) is ammonia stemming from the animal's uric acid catabolism (Boyle 1975). Both adult and aposymbiotic juvenile worms produce nitrogen waste (i.e. uric acid/ammonia) that is recycled by the algae for protein synthesis. In juveniles, uric acid crystals accumulate until photosynthesis sets in, then decline once photosynthesis is fully operational (Douglas 1983a).

According to the literature (Oshman 1966; Nozawa et al. 1972; Muscatine et al. 1974; Meyer et al. 1979), microalgal photosynthetic activity provides all of the energy and nutrients (proteins, polysaccharides, lipids) for feeding the worm. However, strict photo-autotrophy has never been formally demonstrated for this association, and one cannot rule out a mixotrophic regime: $S$. roscoffensis could indeed take up some additional organic molecules released by benthic organisms, including the environmental microbiome.

The paucity of data describing the trophic relationship between $S$. roscoffensis and T. convolutae prevents one from assigning a mutualistic status between these organisms, with the idea of a reciprocal benefit and egalitarian partnership, as has often been claimed. Controversially, recent surveys on photosynthetic endosymbiosis rather suggest that microalgae are exploited by their host (Kiers and West 2016; Lowe et al. 2016).

The $S$. roscoffensis biotope is localized within the upper sandy part of the intertidal zone. During high tide, animals live inside the interstitial sandy net, but as soon as the tide goes out (uncovers the sand) and until it comes in again, the animals are exposed to the sunlight in seepages or pools of seawater.

\subsection{LIFE CYCLE AND REPRODUCTION}

Exploring the diversity and complexity of body plans and their evolutionary and developmental basis requires that the entire life cycle of a species be accessible, from the freshly fertilized oocyte to the gravid reproducer. Controlling all the developmental steps of a species in captivity is essential to undertake necessary experimental steps, including genetic analysis and genome editing. An often-ignored obstacle is a non-negligible investment in time and expenses, a suite of trials, errors and chance findings that slow down access to many crucial stages of ontogenesis.

\subsubsection{Reproductive Organs}

Acoels are hermaphroditic and reproduce by internal fertilization. Sperm cells and eggs develop from neoblast-derived progenitors which divide and mature in the parenchyma in an anterior-posterior gradient (Figure 12.2a, b). Figure 12.2c shows V-shaped bundles of sperm ("sperm tracts"), 

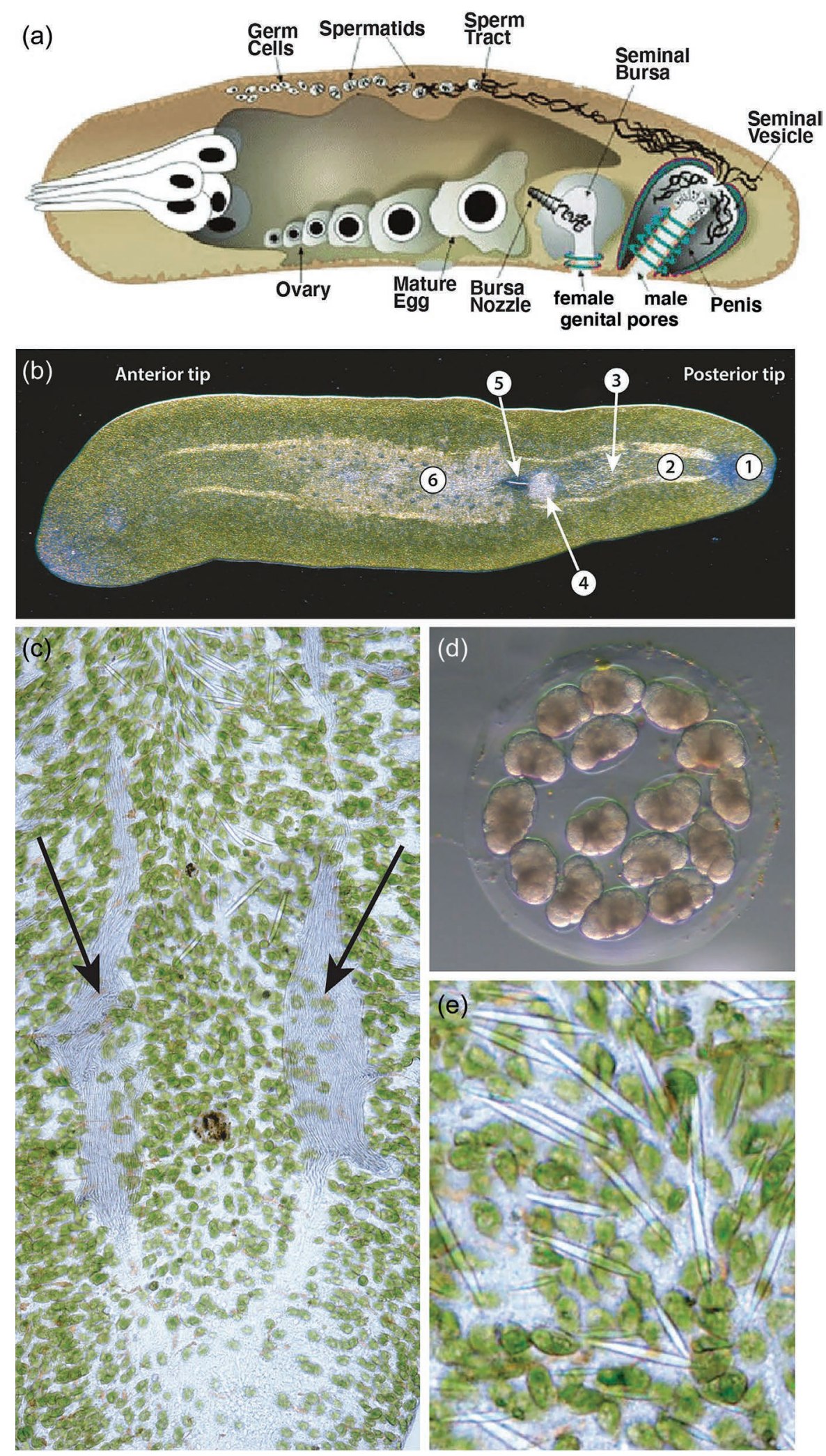

FIGURE 12.2 S. roscoffensis reproduction and anatomy. (a) Schematic sagittal section of acoel illustrating reproductive organs. (b) Photograph showing gravid $S$. roscoffensis reproductive organs: a male gonopore (1) is associated with bundles of mature sperm (2); flanking the gonopore area, there are an important group of saggitocysts (3). A female genital pore (not visible in the picture) gives access to the spermatheca, full of spermatozoids (4) ready to fertilize mature oocytes (6), an event mediated by a bursal nozzle (5). (c) V-shaped bundles of sperm ("sperm tracts"), localized in the posterior part of the body and converging into the male gonopore (invisible in this picture). (d) Cocoon with cluster of cleavage stage embryos. (e) Needle-like structures, the sagittocysts, are found around the genitalia at the end the body. ([a] After Kathryn Apse and Prof. Seth Tyler, University of Maine; with permission. http://turbellaria.umaine.edu/ globalworming/.) 
localized in the posterior part of the body and converging onto the male gonopore. Fertilization is mutual, and sperm are transferred into the seminal bursa and stored there until the eggs are ready to be fertilized (Figure 12.2a, b). Acoel egg and sperm morphologies vary among species, and their characteristics have been used for taxonomic classification (e.g. Achatz et al. 2013). Their copulatory organs are well developed and also show great morphological variety across different taxa. The members of the family Sagittiferidae, for example, develop an antrum that is turned inside out, and the bursa of many sagittiferid species lacks a muscular lining (Kostenko and Mamkaev 1990). In general, the copulatory apparatus of Sagittiferidae is considered a simplified version when compared to those of other families, such as Convolutidae (Zabotin and Golubev 2014).

Most species release the fertilized eggs through the mouth. A few species release eggs through the female genital pore (in those species that have this structure), but all species release the sperm through the male gonopores (Figure 12.2a, b). Genital pores in Acoela are by no means simple structures but have specific associated muscle systems. Symsagittifera roscoffensis has both male and female genital pores. The female genital pore lies in much closer proximity to the male pore than to the mouth, namely at $70 \%$ of the anterior-posterior axis, while the male genital pore is located at the $90 \%$ position (Semmler et al. 2008). The male copulatory organ presents a complex associated musculature. In the position where it is located, the regular grid of circular and longitudinal muscles of the body wall is disrupted, as also happens in the area of the female genital pore. The bursal nozzle is composed of a sclerotized lamellate stack of cells, forming a tubule. This tubiform structure on the seminal bursa is believed to behave like a sperm duct, through which allosperm are transported to the oocytes (Figure 12.2a, b).

In addition to the copulatory organs themselves, certain structures of yet-unknown function are clustered around the male gonopore. Called saggitocysts, these have a needle-like shape with a clear muscle mantle that wraps around an interior protusible filament, being located below the body's muscular grid (Figure 12.2d). Some authors have speculated that the needles might be released and be functionally relevant during copulation (e.g. Yamasu 1991).

\subsubsection{Egg Deposition}

In the natural environment, $S$. roscoffensis is not gravid from July to September and usually reproduces from October to June. In the lab, each gravid adult (Figure 12.2b) maintained in filtered or artificial sea-water spontaneously lays embryos. Embryos are surrounded by a viscous mисоиs layer, a cocoon or capsule (Figure 12.2e). The lack of extracellular coats around oocytes prior to capsule formation is functionally very significant, since it allows the incorporation of multiple cells per capsule (Shinn 1993). Once the cocoon with a diameter of approximately 750 micrometers is finished, the adult deposits the eggs inside it. The number of eggs inside each cocoon can reach a maximum of 30. After four to five days of development, embryos become actively moving transparent juvenile flatworms, approximately 250 micrometers long (Figure 12.1d). After some hours, the juveniles hatch from the cocoon. The absence of microalgae in the juvenile tissues indicates that the transmission of the microalgae is not vertical (i.e. transmission through the oocytes) but horizontal: the free-living microalgae live in the sand and seawater of flatworm's habitat. In the lab, without providing the free-living algae, the juvenile reared in sterile seawater do not survive more than 10 to 15 days, indicating that this partnership is obligatory with respect to the animal.

\subsection{ANATOMY}

\subsubsection{General Architecture Of Cells and Tissues}

As a member of the clade Acoelomorpha, S. roscoffensis lacks a body cavity. A body wall, consisting of processes of epidermal cells and muscle cells, encloses a solid parenchyma whose cells serve the digestion and distribution of nutrients. Embedded in the parenchyma are the nervous system, a variety of glands and the reproductive organs (Ehlers 1985; Rieger et al. 1991).

A fundamental aspect of acoelomorph cellular architecture is the highly branched nature of virtually all cell types. Cells possess a cell body, formed by the nucleus surrounded by scant cytoplasm, and one or (more often) multiple processes which emerge from the cell body (Ehlers 1985; Rieger et al. 1991; Figure 12.3a, b). Processes display a great variety of shapes depending on the type of cell considered. There is the main, or "functional" process(es), next to one or more leaf-like ensheathing processes that many cells project around neighboring structures. Epidermal cells, for example, emit their one "connecting" process radially toward the periphery, where it spreads out to form a large (compared to the size of the cell body), flattened layer that displays the complex ultrastructural features, such as microvilli and cilia, intercellular junctional complexes and epitheliosomes (Rieger et al. 1991; Lundin 1997; Figure 12.3b, c and see subsequently). Additional branched and variably shaped processes of the epidermal cell body project horizontally and intermingle with peripheral nerves, muscle fibers and parenchymal cells (Figure 12.3b, c). Similar to epidermal cells, muscle cells give rise to connecting processes which branch out into long, slender fibers (myofibers) that contain contractile actin-myosin filaments (myofilaments; Figure $12.3 \mathrm{~b}, \mathrm{c})$. Many cells, including muscle and glands, possess a third type of thin, cylindrical process that enters the neuropil of the central nervous system (see subsequently).

Their branched anatomy implies that the cell bodies of epidermal cells or muscle cells (and other cell types) are located at a distance from their "functional parts", that is, the myofibers or epithelial processes forming the body wall. Cell bodies are embedded in the parenchyma, where they are arranged as an irregular layer ("cell body domain") around 
(a)

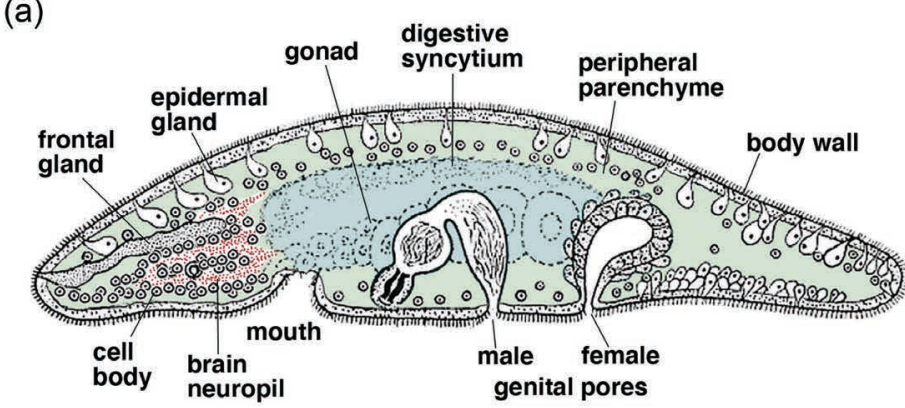

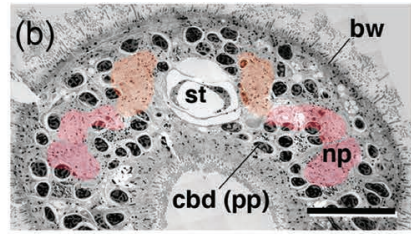

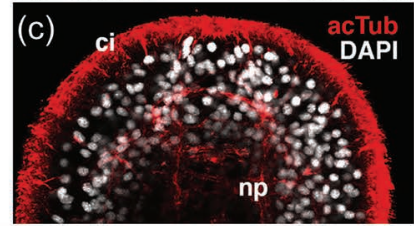

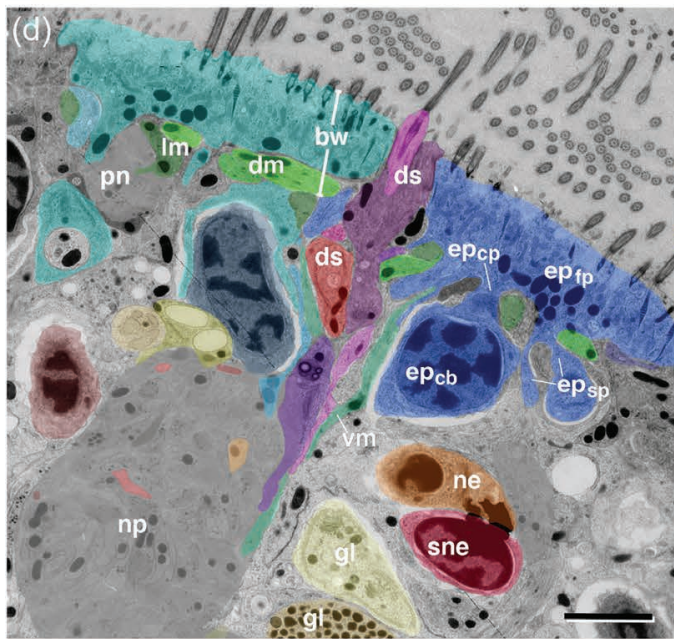
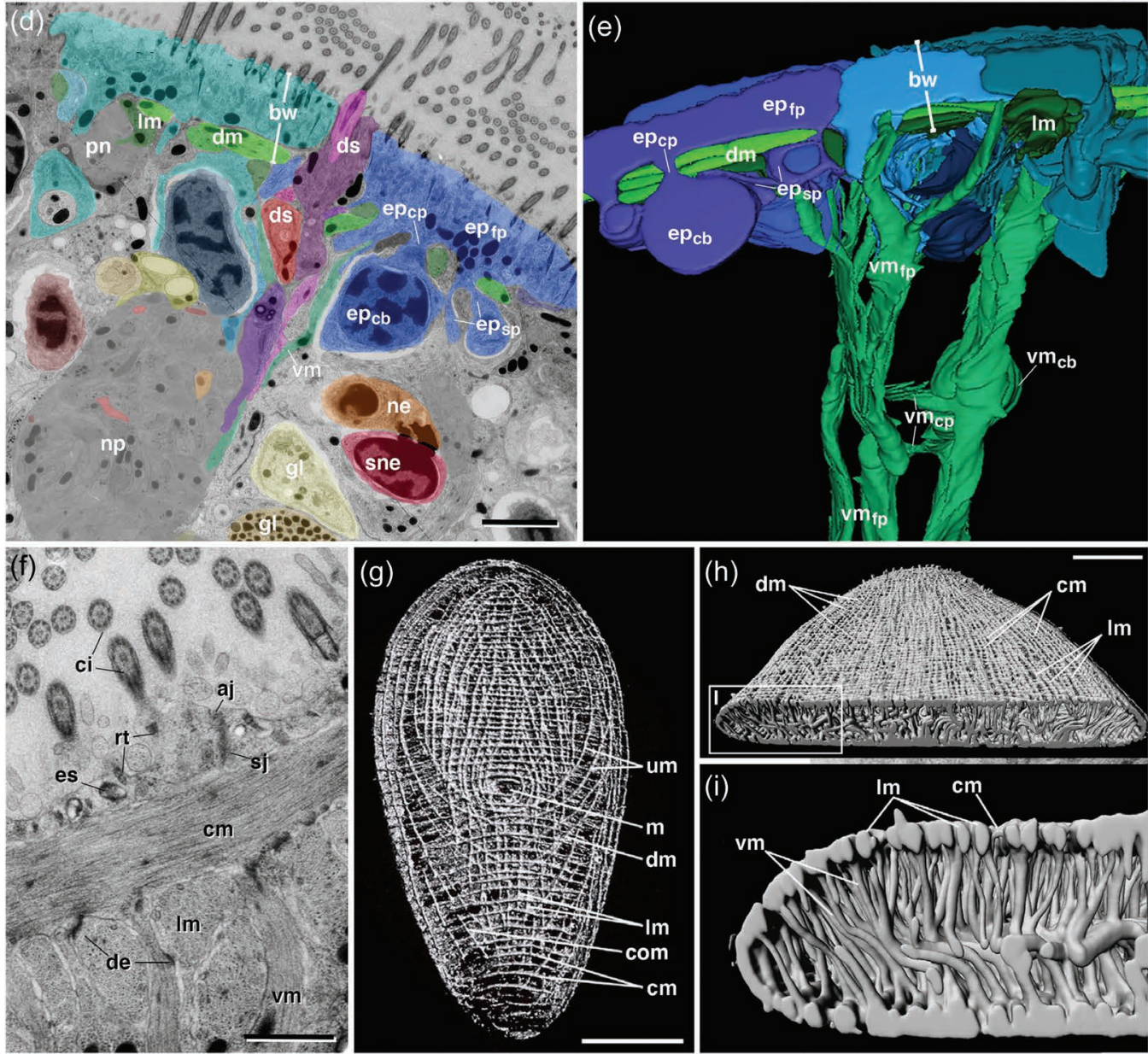

FIGURE 12.3 Anatomy of S. roscoffensis. (a) Schematic sagittal section of acoel (modified from Hyman 1951). (n) Ultrathin crosssection of juvenile $S$. roscoffensis at level of statocyst (st), showing body wall (bw), domain of cell bodies (cbd), sunken into peripheral parenchyma (pp) and neuropil (np). (c) Confocal section of juvenile S. roscoffensis labeled with anti-acetylated tubulin (acTub, red; marking epidermal cilia [ci] and neuronal fibers forming neuropil [np]). (d) Ultrathin cross-section of juvenile S. roscoffensis, showing structures of bodywall (bw), peripheral parenchyma/cell body domain, and neuropil (np). Different cell types are rendered in shades of blue (epidermal cells), green (muscle cells), red (neurons) and yellow (gland cells). Basic architecture of acoel cell types is shown for epidermal cell at upper right, for which cell body $\left(\mathrm{ep}_{\mathrm{cb}}\right)$, connecting process $\left(\mathrm{ep}_{\mathrm{cp}}\right)$, functional process $\left(\mathrm{e}_{\mathrm{fp}}\right)$ and sheath processes $\left(\mathrm{ep}_{\mathrm{sp}}\right)$ are visible. Muscle cell fibers include longitudinal fibers $(\mathrm{lm})$, diagonal fibers $(\mathrm{dm})$ and vertical fibers $(\mathrm{vm})$. A bundle of peripheral sensory dendrites (ds; shades of purple) penetrate the bodywall. (e) 3D digital model of juvenile $S$. roscoffensis bodywall, showing partial reconstructions of three epidermal cells (blue) and vertical muscle cell (green). Components of the epidermal cell on the left and of the muscle cells are indicated. Both cells are composed of a cell body $\left(\mathrm{ep}_{\mathrm{cb}}, \mathrm{vm} \mathrm{m}_{\mathrm{cb}}\right)$, connecting process $(\mathrm{es})\left(\mathrm{ep}_{\mathrm{cp}}, \mathrm{vm}_{\mathrm{cp}}\right)$, functional processes $\left(\mathrm{ep}_{\mathrm{fp}}\right.$, $\mathrm{vm}_{\mathrm{fp}}$ ) and sheath processes (ep $\mathrm{p}_{\mathrm{sp}}$; no sheath processes are formed by the muscle cell shown). (f) Electron micrograph of cross-section of body wall of juvenile $S$. roscoffensis, showing ultrastructural aspects of epidermal cells (ci: cilia; es: epitheliosome; rt: rootlet of cilium; aj: adherens junction; sj: septate junction) and body wall-associated muscle fibers (cm: circular muscle; lm: longitudinal muscle; vm: vertical muscle; de: desmosomes between muscle fibers). ( $\mathrm{g}-\mathrm{i})$ 3D rendering of $S$. roscoffensis muscles labeled by phalloidin. Ventral view (g), dorso-posterior view (h), frontal view (i; digital cross-section). Other abbreviations: com: ventral cross-over muscles; m: mouth; ne: central neuron; pn: peripheral nerve; sne: sensory neuron; um: U-shaped muscles. Scale bars: 20 micrometers (b, c); 2 micrometers (d, e); 1 micrometer (f); 50 micrometers (g). ([g-i) From Semmler et al. 2008, with permission.) 
an interior neuropil and digestive syncytium (Figure 12.3d, e; see subsequently). Importantly, bodies of different cell types, in particular neurons, muscle cells and gland cells, appear to be intermingled in the cell body domain rather than forming separate organs or tissues (Figure 12.3a; Arboleda et al. 2018; Gavilan et al. in prep).

The unusual cellular architecture in acoelomorphs has been related to the absence of a basement membrane, another unique character of this clade (Smith and Tyler 1985; Rieger et al. 1991; Morris 1993; Tyler and Rieger 1999). In other animals, a basement membrane, composed of robust and highly interconnected filamentous proteins including collagens and laminins, separates epidermal cells and muscle cells and surrounds internal organs such as the intestinal tube, glands and nerves. The basement membrane also provides the point of anchorage between muscles and epidermis or other epithelial tissues. As a result, cells have a more or less symmetric shape, resembling cubes or cylinders, with the cell body included within these shapes. In acoelomorphs, lacking a basement membrane, cell bodies can be extruded out from their working parts, intermingle and adopt highly irregular, branched shapes.

\subsubsection{EPIDERMIS}

The squamous functional processes of epidermal cells that cover the surface of the animal are of a fairly regular polygonal shape. Epidermal cells of $S$. roscoffensis are interconnected by belt-like junctional complexes, consisting of an apical adheres junction followed proximally by a prominent septate junction (Rieger et al. 1991; Lundin 1997; Figure 12.3f). Epidermal motile cilia power locomotion of the animal. Following the ground pattern of acoelomorphs and flatworms in general, epidermal cells are multiciliated (Figure 12.3f). Cilia are anchored by vertically oriented striated rootlets, conspicuous cytoskeletal elements consisting of the conserved protein rootletin (Yang et al. 2002). Since rootlets are interconnected by evenly sized horizontal processes, cilia of each epidermal cell form a highly symmetric array. More irregularly spaced microvilli are interspersed with the cilia. Another characteristic of epidermal cells are closely packed, moderately electron-dense vesicles called epitheliosomes, or ultrarhabdites (Rieger et al. 1991). Epitheliosomes are of rounded or elongated shape and can be seen to be extruded from the apical membrane to release their presumably mucous content (Figure 12.3f).

\subsubsection{Muscle System}

The musculature of the acoelomorph body wall is formed by three layers of myofibers, circular fibers, diagonal fibers and longitudinal fibers (Rieger et al. 1991; Hooge 2001). In early larval $S$. roscoffensis, one finds approximately 60 circular and 30 longitudinal fibers; in adults, these numbers increase to 300 and 140, respectively (Semmler et al. 2010; Figure $12.3 \mathrm{~g}-\mathrm{i})$. Note that these numbers do not necessarily reflect the number of muscle cells, since one muscle cell soma can give rise to more than one myofiber (see previously). In addition to the outer muscles, a large number of regularly spaced, short vertical muscle fibers penetrate the parenchyma and nervous system and insert at the dorsal and ventral body wall. Specialized muscle fibers surround the mouth opening (see section on digestive system). In all muscle fibers, myofilaments show a smooth architecture (Figure 12.3f), lacking the Z-discs of striated muscles found in other clades. Myofibers are typically branched near their point of attachments to each other and to epidermal cells (Figure $12.3 \mathrm{e}, \mathrm{f})$ and exhibit electron-dense junctional complexes ("maculae adherentes" or desmosomes; Tyler and Rieger 1999; Figure 12.3f).

The innervation of the musculature of $S$. roscoffensis, as with acoelomorphs in general, is mediated by thin processes branching off the myofibers and extending into peripheral nerves or the neuropil (Rieger et al. 1991). In addition, large numbers of neuronal fibers exiting neuropil and peripheral nerves terminate in close contact to myofibers, as well as epidermal and glandular processes (Gavilan et al. in prep.). The exact mechanism of neural control of muscle contraction and ciliary movement is clearly one of the research areas that needs much attention.

\subsubsection{Central Nervous System}

Acoelomorphs have a central nervous system consisting of an anterior brain, several and paired longitudinal nerve cords that issue from the brain (Martinez et al., 2017). Brain and nerve trunks are formed by neuronal somata that are located in the cell body domain underlying the body wall and a central neuropil enclosed within the cell body domain. The neuropil, labeled by markers such as anti-acetylated tubulin or anti-Synapsin (Bery et al. 2010; Sprecher et al. 2015; Arboleda et al. 2018), is built of stereotypically patterned elements and provides an internal scaffold to which other cells and organs can be related. In S. roscoffensis, one distinguishes a dorsomedial compartment, dorsolateral compartment and ventral compartment along the dorsoventral axis (Figure 12.4a, b). As described for other acoelomorph taxa (Martinez et al. 2017), the brain neuropil of S. roscoffensis encloses in its center the statocyst, which demarcates within each of the compartments an anterior domain (relative to the midpoint of the statocyst) and a posterior domain (Figure 12.4a, b). Three commissures connect these compartments: the ventro-anterior commissure (vac) arises from the convergence of the anterior ventral and anterior dorso-lateral compartment, the dorso-anterior commissure (dac; c1 in Bery et al. 2010) interconnects the anterior dorso-medial compartments right in front of the statocyst and the dorso-posterior commissure (dpc; c2 in Bery et al. 2010) forms a bridge between the posterior dorso-medial compartments. The nerve cords projecting posteriorly from the brain include the dorso-medial cord (dmc, originating from dorsomedial compartment), dorsolateral cord (dlc) and ventrolateral cord (vlc) (Bery et al. 2010). The cords are also interconnected by several anastomoses and commissures. 

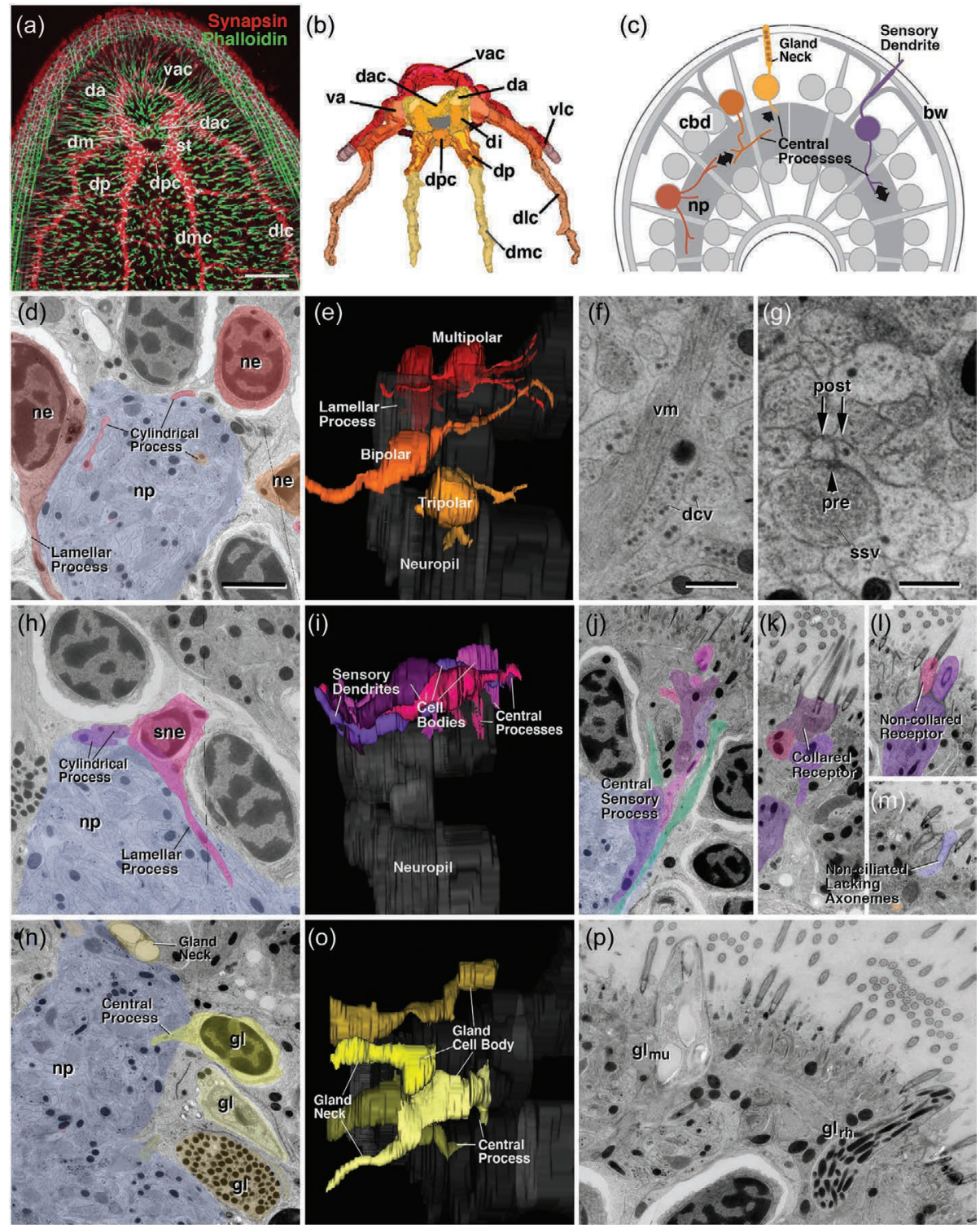

FIGURE 12.4 Anatomy of S. roscoffensis. (a, b) Central nervous system and neuropil. (a) A confocal section of adult S. roscoffensis. Muscles are labeled by phalloidin (green), central neuropil by an antibody against synapsin (red). (b) A 3D digital model of neuropil with different neuropil domains rendered in different colors. Neuropil domains visible in the dorsal view shown include dorso-anterior compartment (da), dorso-intermediate compartment (di; flanking statocyst shaded gray), dorso-posterior compartment (dp), and ventroanterior compartment (va). The three brain commissures connecting right and left compartments are the ventro-anterior (ring) commissure (vac), dorso-anterior commissure (dac) and dorso-posterior commissure (dpc). Three pairs of nerve cords exit the brain: the dorso-medial cord (dmc), dorso-lateral cord (dlc) and ventro-lateral cord (vlc). (c) Schematic section of S. roscoffensis, illustrating the processes of neurons (red), sensory neurons (purple) and gland cells (yellow) in relationship to the body wall (bw), neuropil (np) and cell body domain (cbd). Thick black arrows symbolize synaptic interaction between central processes of the cells shown and elements of the neuropil. (d-g) Cytological details of central neurons. (d) Cell bodies surrounding neuropil (np; shaded blue). Three cell bodies belong to central neurons (ne; rendered in shades of red). Central neurons emit processes into neuropil. In some cases, processes exhibit particular sheath-like shapes ("lamellar processes"), aside from the cylindrical processes typical for neurons in general. (e) 3D digital model (lateral view) of four representative partially reconstructed central neurons exhibiting different shapes. (f, g) Electron microscopic sections of neuropil at high magnification. Note the high proportion of axons with dense core vesicles (dcv). Vertical muscle fibers (vm) penetrate neuropil and could receive extra-synaptic input from these axons. (g) An example of synaptic connection between large presynaptic element (pre) with small synaptic vesicles (ssv) and two small postsynaptic elements (post). (h-m) Cytological details of sensory neurons. As shown in (h), cell bodies of sensory neurons (sne) frequently lie adjacent to the neuropil and emit cylindrical or lamellar processes into the neuropil. (i) Shapes of ciliated sensory neurons (lateral view). (j) Bundle of four sensory processes linking neuropil to the body wall. $(\mathrm{k}-\mathrm{m})$ Three different types of frequently seen sensory endings, a collared receptor (k), non-collared receptor (l) and non-ciliated receptor (m). (n-p) Details of gland cell structure. In (n), cell bodies of three gland cells (rendered in shades of yellow) surround the central neuropil (np). One gland cell emits a central process into the neuropil. Digital 3D models shown in (o) illustrate representative gland cells (lateral view). (p) Section of body wall with endings of two different types of gland cells, a mucus gland cell with large electron-lucent vesicles $\left(\mathrm{gl}_{\mathrm{mu}}\right)$ and a rhabdoid gland cell $\left(\mathrm{g}_{\mathrm{lrh}}\right)$ with elongated, electron-dense inclusions. Scale bars: 40 micrometers (a); 2 micrometers (d, h-p); 0.5 micrometers (f, g). (From Sprecher et al. 2015, with permission.) 
Neuronal cell bodies (somata) of the $S$. roscoffensis nervous system are small and have a round heterochromatinrich nucleus (Figure 12.4d). Based on light-microscopic analysis, the larval brain contains an estimated 800 somata overall, but more precise numbers have to await serial EM analysis, since somata of neurons located in the diffuse cell body domain that surrounds the neuropil cannot be told apart with certainty from cell bodies of muscle cells or gland cells. EM reconstruction shows that many neurons are bipolar, extending an anterior process that in many cases may reach the epidermal surface to end as a sensory receptor, and one or more posterior or central process(es) that reaches into the neuropil, where it shows a modest amount of branching (Figure $12.4 \mathrm{~d}, \mathrm{e}$ ). Along with neuronal processes, central extensions of muscle cells and gland cells also form part of the neuropil (Figure 12.4c).

Based on the types of vesicles they contain, neuronal processes of acoelomorphs were divided into four classes (Bedini and Lanfranchi 1991; Bery et al. 2010), including fibers with small clear vesicles $(20-40 \mathrm{~nm})$, which are associated with the "classical" transmitters acetylcholine, GABA or glutamate, and dense vesicles $(70-90 \mathrm{~nm})$, which resemble the dense core vesicles that, in vertebrates and many invertebrates alike, have been described to contain neuropeptides (Figure 12.4f, g). As in these other species, many neurons of S. roscoffensis have both types of vesicles. What stands out, however, is the large proportion of neuronal processes with dense vesicles, a finding that matches descriptions of light microscopic studies detecting peptide transmitters in large neuron populations in acoelomorphs (Reuter et al. 2001). Aside from small clear vesicles and dense vesicles, two other types with so far unknown significance and neurotransmitter content were described for acoelomorphs: another type of "dense core vesicles" (60-120 nm), containing small, dense centers surrounded by a light halo (not to be confused with the peptide-containing dense core vesicles in vertebrates or insects) and large irregularly shaped clear vesicles (20-400 nm; Bedini and Lanfranchi 1991).

Neuronal processes containing small clear vesicles in conjunction with membrane densities can be recognized as synapses (Bedini and Lanfranchi 1991; Bery et al. 2010; Figure $12.4 \mathrm{~g})$. However, thus defined synapses are relatively few in number, at least in the larval brain, and it is very possible that neural transmission relies heavily on extra-synaptic transmitter release. This is made all the more likely looking at the processes with dense vesicles, which fill the entire length of neurons, including the cell body, and peripheral processes. Peptide release from dense core vesicles in vertebrates has been definitively shown to occur extrasynaptically ("volume release") in many instances (Fuxe et al. 2007).

\subsubsection{Peripheral Nervous System and Sensory Receptors}

The peripheral nervous system consists of sensory receptors integrated in the body wall and an anastomosing meshwork of thin "nerves" that contain fibers formed by sensory receptors, muscle cells and gland cells, as well as cells effector cells ("motor neurons") that, aside from processes in the neuropil, project processes through the peripheral nerves into the periphery. Sensory neurons form part of the cell body domain surrounding the neuropil (Figure 12.4c, h, i). Their peripheral dendrites project into the body wall (Figure $12.4 \mathrm{j}$ ), where they terminate as conspicuous elements that have been described for many flatworms, including acoels (Rieger et al. 1991). Unlike epidermal cells, sensory receptors typically contain a single cilium, aside from other apical membrane specializations. Based on these specializations, one distinguishes collared receptors from non-collared receptors (Bedini et al. 1973; Todt and Tyler 2006). In the former, a central cilium is surrounded by a ring (collar) of long, stout microvilli; this collar is lacking in the latter class. Both classes are further subdivided into several types (Todt and Tyler 2006). In S. roscoffensis, three types of sensory receptors have described, including non-collared receptors with a hollow ciliary rootlet containing a granulated core (Type 3 of Todt and Tyler 2006; Figure 12.41), collared receptors with rootlets (Type 4) and collared receptors with granular body (Type 5; Figure 12.4k). Another frequently encountered type of presumed receptors are non-ciliated endings (Figure 12.4m). Receptors are distributed in characteristic patterns all at different positions (Bery et al. 2010). Nothing is known about the specific modalities and functions of sensory receptors.

Two other sensory elements, the statocyst and eyes, are surrounded by neuropil and thereby form part of the CNS (Figure 12.1c). The statocyst, thought to sense gravity, is formed by a capsule of two parietal cells enclosing a cavity that houses a specialized statolith cell (lithocyte; Ferrero 1973; Ehlers 1991). A small group of specialized muscle cells inserts at the capsule. No recognizable sensory neuronal structures are associated with the statocyst, and it has been proposed that gravity-induced displacements of the statolith could inform the CNS by affecting the muscles by which the statocyst is suspended.

The eye of convolutid acoels, including $S$. roscoffensis, is embedded into the brain on either side of the statocyst. The eye consists of a pigment cell with electron-dense granules and crystalline inclusions ("platelets") that may act as reflectors; enclosed by the pigment cell are two to three receptor cells with axons connecting to the neuropil (Yamasu 1991). Unlike most photoreceptors described for other taxa, acoel photoreceptors cells lack conspicuous microvilli or cilia.

\subsubsection{Glandular System}

Glands are unicellular, consisting of individual gland cells that constitute a major part of the acoelomorph body in terms of number and function. As stated for epidermal and muscle cells, gland cells consist of a cell body that forms part of the internal cell body domain and one or more elongated processes ("gland necks") that project peripherally and open to the outside (Figure 12.4c, n, o). Certain clusters of gland cells, located posteriorly of the brain, project their long 
necks forward through the neuropil and open at the anterior tip of the body, some of them in an acoelomorph-characteristic pore, the "frontal pore" (Pedersen 1965; Smith and Tyler 1986; Klauser et al. 1986; Ehlers 1992; Figure 12.3a). Cell bodies and gland necks contain secretory vesicles of different shape and texture by which gland cells have been divided into different classes, as summarized in the following. Gland necks carry a characteristic array of microtubules around their periphery. In addition to secretory gland necks, many gland cells appear to have central processes that invade peripheral nerves or the neuropil. These processes, like the ones formed by myofibers (see previously), may mediate the connection between nerve impulses and secretory function (Figure 12.4c, n).

Functionally and biochemically, acoelomorph gland secretions include mucus (mucopolysaccharides) that serves for locomotion, attachment and protection, as well as proteinaceous enzymes for digestion and degradation of macromolecules. Mucus-producing glands, called cyanophilic glands in the classical light microscopy literature, are structurally associated with densely packed, electron-lucent vesicles with a rounded or oval shape (Pedersen 1965; Rieger et al. 1991). Gland cells of this type open in the frontal pore but also occur all over the body surface of $S$. roscoffensis. Aside from gland cells with electron-lucent inclusions, a variety of cells with electron-dense vesicles of different sizes and shapes have been described for the acoelomorphs (Smith and Tyler 1986; Klauser et al. 1986; Todt 2009). These have been given different names (e.g. "ellipsoid" glands, "target glands", "alcian blue-positive rhabdoid glands") but cannot be assigned to specific functions. In the larva of $S$. roscoffensis, we detect glands with large, electron-lucent inclusions (mucus glands; Figure $12.4 \mathrm{p}$ ) all over the body but preferentially anteriorly and ventrally; in addition, there are three clearly distinguishable types of gland cells with electron-dense inclusions (Gavilan et al. in prep):

1. A rare type we call a rhabdoid gland cell, with elongated inclusions of approximately $500 \mathrm{~nm}$ length and $100 \mathrm{~nm}$ diameter (Figure 12.4p).

2. Glands with pleomorphic vesicles: Inclusions are more rounded than those of rhabdoid glands and possess different diameters and electron densities (Figure $12.4 \mathrm{n}$, bottom). Rhabdoid glands and pleomorphic glands are located ventro-anteriorly.

3. Glands with mixed electron-dense and electronlucent vesicles: These are more numerous and ventro-laterally overlie the ventral nerve cord.

\subsubsection{Parenchyma and Digestive Syncytium}

The name-giving feature of acoels is their lack of a gut cavity. The interior of the animal is filled with a solid parenchyma that is divided into a central and peripheral domain (Smith and Tyler 1985; Gavilán et al. 2019). The central parenchyma is typically a syncytium ("digestive syncytium") formed by the merger of multiple endodermal cells; in the larva of $S$. roscoffensis, the digestive syncytium contains an estimated 6-10 nuclei (Gavilan et al. in prep.). At a mid-ventral position, the digestive syncytium is in contact with the interior through a pore ("mouth") in the epidermal covering. A pharynx, in the shape of an invagination of the ventral epidermis surrounded by specialized muscle and neural elements, is absent (Todt 2009; Semmler et al. 2010). Only a slender muscle ring from which a few fibers radiate outward marks the mouth. In addition, several ventral longitudinal muscle fibers cross over the midline right behind the mouth, giving rise to the U-shaped muscles that are the characteristic of the derived acoel clade of "Crucimusculata" to which S. roscoffensis belongs. It is thought that contraction of these fibers tilts the mouth forward, facilitating the uptake of food stuff.

The digestive syncytium is filled with a great diversity of organelles related to phagocytosis and digestion. In $S$. roscoffensis, symbiotic algae of the genus Tetraselmys are taken into the syncytium, where they lose part of their cell wall. The digestive syncytium emits processes that reach throughout the entire body, ensheathing (parts of) many cell bodies in the cell body domain and wrapping around peripheral nerves, muscle fibers and epidermal processes (Smith and Tyler 1985; Gavilan et al. in prep). One has to assume that this architecture enables the syncytium not only to digest but also distribute nutrients throughout the body. In the case of $S$. roscoffensis, algae ingested at the early larval stage multiply within vacuoles of the digestive syncytium (Oshman 1966; Douglas 1983b). In the adult, algae form a dense layer underneath the body wall, interspersed with epidermal and muscle processes (Figure 12.1d). EM analysis indicates that algae remain enclosed within the processes of the digestive syncytium (Douglas 1983b).

The peripheral parenchyma is formed by cells called "wrapping cells" (Smith and Tyler 1985) which are similar in ultrastructure to the digestive syncytium. They also form elaborate sheaths around other cells, interdigitating with processes of the digestive syncytium. It has been proposed that wrapping cells merge with the digestive syncytium, manifesting part of a dynamic process whereby newly generated cells proliferated from neoblasts (see section 12.4.8) mature, have a transient life as wrapping cells and end up as part of the central syncytium (reviewed in Gavilán et al. 2019).

\subsubsection{Neoblasts (Stem Cells)}

Regeneration of acoel tissues is a well-known phenomenon. This process depends on the deployment of a pool of stemlike cells called neoblasts that are present within parenchymal tissues (De Mulder et al. 2009; Srivastava et al. 2014). In all species in which neoblasts have been mapped, these cells are distributed in two lateral bands and mostly excluded from the head region. Neoblasts are easily identifiable by their intensive basophilic cytoplasm and relative scarcity of cytoplasmic organelles (Brøndsted 1955). Neoblasts are the only dividing cells in adult organisms, and they have the potential to differentiate into all, or most, cell types during regeneration (Gschwentner et al. 2001). In Symsagittifera 
roscoffensis, neoblasts have been detected using EdU labeling, and their global distribution is similar to what has been reported for other acoels (Arboleda et al. 2018). Using more detailed TEM images, these cells can be seen characteristically embedded in the parenchyma, showing the typical high nuclear/cytoplasmic ratio-a characteristic shared by all known neoblasts, including those of the distantly related Platyhelminthes phylum. After amputation of anterior structures (unpublished data), neoblasts start to proliferate immediately, in the next few hours, and are subsequently mobilized to the wound area. After this initial burst period, the number of neoblasts seems to decrease, likely due to their differentiation into newly formed tissues. Interestingly, the analysis of TEM data has shown that at least some neoblast groups (composed of three to four cells each) seem to be associated with the nerve cord and muscle fibers. This could reflect a close interaction of neoblasts with these tissues, both in regular homeostasis and in regeneration. A fraction of the cells with neoblast characteristics seem to be undergoing differentiation. The cytoplasm of these differentiating cells extends processes filled with microtubules and vesicles in between the surrounding neuronal somata or epidermal cells (Bery et al. 2010). Regeneration in Platyhelminthes and Acoela has been shown to be regulated by neural trophic factors with positional cues from musculature (Hori 1997; Hori 1999; Raz et al. 2017). This suggests that S. roscoffensis neoblasts may be actively receiving signals from their close environment (the niche?). A recent study from the Sprecher laboratory using single-cell technology (data not shown here) elucidates the molecular signatures characteristic of neoblasts in Isodiametra pulchra. These findings should enable a more detailed characterization of the regulatory factors that control the stemness state of neoblasts in acoel species and also how they make decisions to differentiate.

\subsection{EMBRYOGENESIS}

The embryonic development of acoels is poorly understood. Various problems, mostly practical in nature, have impaired the study of early acoel embryos. In fact, the lineage of early blastomeres has been described in detail for only one acoel species, Neochildia fusca (Henry et al. 2000). Later stages of development in this species have also been studied, in combination with molecular markers, by Ramachandra et al. (2002).

All acoel embryos studied thus far-including our species, Symsagittifera roscoffensis (Georgévitch 1899; Bresslau 1909) - appear to share the same pattern of early divisions (Georgévitch 1899; Bresslau 1909; Apelt 1969; Boyer 1971; Henry et al. 2000). Acoels' unique pattern of cleavage is termed "duet spiral" cleavage in order to differentiate it from the more common "quartet spiral" cleavage. It is important to note that although the acoel's unique form of cleavage was recognized early on by researchers such as Ernst Bresslau, it was still considered a modified version of the typical "spiral cleavage". Barbara Boyer and colleagues introduced the term "duet spiral" in 1996, after it became clear that the pattern is in fact very specific to acoels (Boyer et al. 1996).

As explained by Henry et al. (2000), the "duet" form of cleavage is characterized by the presence of a second cleavage plane oblique to the animal-vegetal axis. At the fourcell stage, the first cleavage plane corresponds to the plane of bilateral symmetry. The first two divisions give rise to four equal blastomeres, while the third division generates the first set of four micromeres in the animal half. The first division plane corresponds to the plane of bilateral symmetry, and the second cleavage always occurs in a leiotropically oblique plane relative to the animal-vegetal axis. After this second division, all remaining cleavages are symmetrical across the sagittal plane. The second sets of micromeres are given off of the macromeres. These micromeres will all give rise to the ectoderm. A fourth quartet of micromeres, plus the macromeres, will give rise to the endoderm. Finally, derivatives of some of these micromeres will give rise to the mesoderm.

The early embryos of Symsagittifera roscoffensis were described for the first time by Jivoïn Georgévitch in 1899 , using histological sections in paraffin. He observed that the embryos are enveloped in a thick, cocoon-like membrane where they develop more or less synchronously for one week outside the animal, until hatching. The first embryonic division begins after the fertilized egg is enveloped in the cocoon membrane and outside the animal. Cleavage follows, and the embryo reaches the blastula state at the eightblastomere stage. Here, the ectodermal cells occupy the dorsal part of the embryo, and the endodermal cells occupy the ventral part of the embryo. After a few more divisions, the embryo reaches the gastrula stage. This is achieved through the process of epiboly, in which the ectodermal cells-originally in the dorsal part-migrate downward to cover the whole embryo. No gastric cavity is observed in the gastrula, similar to Gardiner's (1895) observations in Polychaerus. At later stages-but before hatching-the primordia of the different tissues can be observed. Outside the embryo, the ciliary cover of the epithelial cells is clearly visible. These organ systems further mature after hatching, reaching adult-level complexity a few weeks later. The previous descriptions, while correct overall, were immediately criticized by Ernst Bresslau for inaccuracies in many details. In 1909, Bresslau published a more accurate account of each cleavage stage, from the 2-cell stage to the 32-cell stage (Figure 12.5a), Using live embryos, he was able to describe the different divisions (and their relative orientations) in great detail. Initial unequal cleavages led to a blastula at the eight-cell stage. He insisted that the changes in the configuration of the blastomeres between the 8-cell and 16-cell stages could be understood as a gastrulation process, whereby the 14 micromeres produced thus far undergo a process of epiboly that internalizes the $3 \mathrm{~A} / \mathrm{B}$ macromeres, the founder cells of the endo-mesoderm (Figure 12.5a). All in all, Bresslau provided the first accurate description of the first stages of development, consistent in many details with Henry et al.'s (2000) report on Neochilida fusca using 

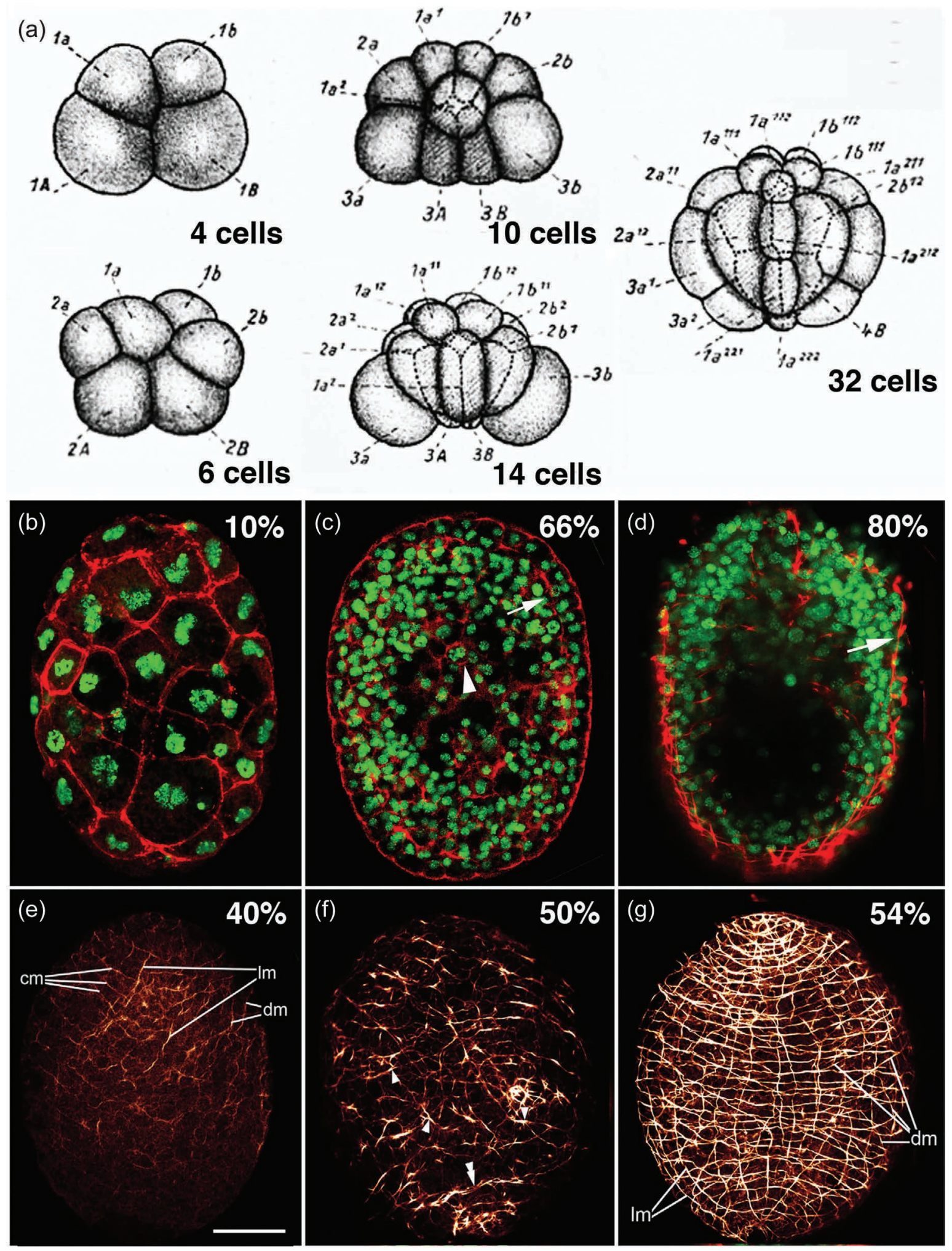

FIGURE 12.5 Embryonic development of S. roscoffensis. (a) Cleavage stages 4 cells to 32 cells, lateral view. Numbering of blastomeres by the author. (b-d) Horizontal confocal sections of S. roscoffensis at $10 \%$ development (b), $66 \%$ development (c) and $80 \%$ development (d). Nuclei are labeled with Topro (green). Phalloidin (red) labels cell membrane associated actin filaments as well as myofilaments. Arrow in (c) points at basal membranes of ectoderm cells and emerging myofilaments; note that ectodermal (epidermal) nuclei still form a layer peripherally of this boundary. Arrowhead indicates membrane around internal endodermal cells. At later stages (d), most epidermal nuclei have sunk below the level of body wall muscle fibers (arrow); endoderm cells have fused into digestive syncytium. (e-g) Emergence of muscle fibers, labeled with phalloidin (orange) between embryonic stages $40 \%$ and $54 \%$. Z-projection, dorsal view. Abbreviations: cm: circular muscles; dm: diagonal muscles; 1m: longitudinal muscles. Scale bar: 50 micrometers (b-g). ([a] From Bresslau 1909; [e-g] from Semmler et al. 2008, with permission.) 
lineage tracing. Moreover, Bresslau is the first to present a lineage map of the Convoluta (Symsagitifera) embryo, an impressive feat of detailed observation at the beginning of the 20th century. Notably, the duet spiral cleavage characteristic of acoels is not present in members of the closely related Nemertodermatida order (Børve and Hejnol 2014), which exhibit a slightly different pattern of blastomere divisions during early embryonic development.

The embryological origin of tissues hasn't been thoroughly studied in $S$. roscoffensis. Following cleavage and gastrulation, the embryo forms a solid mass of cells, with an outer epithelial layer giving rise to the epidermis and an inner mass of cells to digestive cells (Figure 12.5b), parenchyma and musculature. It is not known whether, at this stage, progenitors of neurons or gland cells are already part of the inner mass or are still integrated in the epithelial outer layer. Until about $60 \%$ of development, a regular surface epithelium remains visible; subsequently, cell bodies of epidermal cells, as well as all other cells which potentially are initially at the surface, like glands or sensory neurons, sink inward (Figure 12.5c, d).

The genesis of the musculature has been observed in detail using F-actin labeling (Semmler et al. 2008). The process of myogenesis is very similar to that observed in another acoels (i.e. Isodiametra pulchra: Ladurner et al. 2000 or Neochildia fusca: Ramachandra et al. 2002). The latter study shows the initial stages of muscle formation, probably common to many acoels, with the first signs of musculature being myoblasts forming a thin layer underneath the epidermis, laterally and posteriorly to the brain. Some early muscular fibers penetrate the brain. During the very first days of Symsagittifera embryo development, a grid of circular and longitudinal muscles appears, with circular muscles preceding longitudinal ones. Myogenesis in the anterior part of the animal occurs first and then proceeds in an anterior-posterior progression (Figure 12.5e). Muscular circular fibers are added by a process involving the branching of previous ones (Figure 12.5f). The grid of muscles is more regular in the dorsal part of the embryo than in the ventral, probably due to the need to accommodate additional muscles in ventral structures such as the mouth and the copulatory organs (Figure $12.5 \mathrm{~g}$ ). The embryos hatch with a basic grid composed of about 30 longitudinal and 60 circular muscles (Semmler et al. 2008). During the later development, additional muscles are incorporated, including specialized muscles around the mouth and the copulatory system, plus a whole array of transversal (dorso-ventral) fibers. The adults have a total of about 300 circular muscles and 140 longitudinal ones.

The embryonic origin of the brain and the neural chords hasn't been studied in detail, but it is assumed to occur in early embryogenesis, based on early embryonic expression (bilateral lobes) of some bHLH "neurogenic" genes (Perea-Atienza et al. 2018). A better understanding of the genesis of the nervous system is derived from the study of Neochildia fusca embryos (Ramachandra et al. 2002). These authors documented the presence in late embryos of the brain primordia, which can be clearly distinguished at the anterior pole of the embryo and consists of an external cortex of neuronal bodies around an internal neuropil. Given the consistency of these observations with those of Perea-Atienza, and with both acoels being members of the same class, Crucimusculata, we can hypothesize that the neurogenesis is following identical, or very similar, paths. A more comprehensive analysis of gene expression patterns during S. roscoffensis embryogenesis is urgently needed in order to understand the mechanisms regulating embryonic development and patterning.

\subsection{REGENERATION}

Acoel flatworms show an enormous capacity for regeneration. The extent of this regeneration varies from species to species, with some even relying on regeneration for reproduction (Sikes and Bely 2010). Investigation of the regenerative capacity of acoels dates back to the beginning of the 20th century, when Elsa Keil (1929) described some histological aspects of regeneration in the acoel flatworm Polychaerus caudatus. Keil's work was a revision of even earlier data provided by Stevens and Boring (1905) and Child (1907). In the 1950s and 1960s, researchers including Steinböck (1954) and Hanson $(1960,1967)$ undertook a more systematic analysis of the regeneration process in some acoel "turbellarians", resulting in the creation of some now-classical monographs.

One interesting aspect of acoel regeneration is that different species have the capacity to regenerate different bodily areas. For example, Symsagittifera roscoffensis and Hofstenia miamia can regenerate the anterior area (Bailly et al. 2014; Hulett et al. 2020), while Isodiametra pulchra can regenerate the posterior area (De Mulder et al. 2009; PereaAtienza et al. 2013). Many other varieties of regeneration have been described for other species (Bely and Sikes 2010). The reasons underlying these different capacities remain unknown.

Symsagittifera roscoffensis is a particularly interesting system in which to study regeneration, since this species has the capacity to regenerate the whole brain anew. This has interesting implications for understanding the mechanisms involved in the regeneration of the nervous tissue. In Symsagittifera roscoffensis, the regeneration of the brain anatomy after amputation takes between one week and ten days, similar to the time taken by Hofstenia miamia. However, some additional structures, such as the statocyst, require a few weeks for complete regeneration. The regenerative process involves the mobilization of stem cells (neoblasts) that begin actively proliferating in response to amputation and subsequently concentrate in the wound area (BG and PM, unpublished data). The active proliferation of neoblasts is followed by a differentiation of mature tissues. A clear blastemal area is missing in this process. Regeneration follows three broad and distinct steps: (1) a contraction of the anterior musculature immediately following amputation; (2) a subsequent closure of the wound 
area; (3) an extension of the three pairs of nerve cords into the anterior domain of the animal's body; and (4) the final connection of these nerves to form two ring-shaped, symmetrical neuronal structures with increasing numbers of mature neurons (i.e. the brain). Based on indirect observations (see Bery et al. 2010), it has been proposed that nerve chords and muscular fibers at the amputation site could somehow guide the process of tissue repair. This would be in line with indications in Hofstenia miamia that muscles provide positional information to regenerating tissue in acoels (Raz et al. 2017), as is also the case in platyhelminth species. The process of regeneration in Symsagittifera roscoffensis has not been well characterized due to a lack of studies using molecular markers. Studies of this nature have been undertaken recently in Hofstenia miamia (Hulett et al. 2020). However, it is important to note that in Symsagittifera, it has been possible to test the functional reconstruction of the brain area using various behavioral tests assessing functions such as phototaxis and geotaxis (Sprecher et al. 2015). These behaviors, though recognized for decades (Keeble 1910), are only now being studied quantitatively (Nissen et al. 2015). Sprecher and colleagues (2015) have used different paradigms to assess the behavior of amputated worms at different stages of recovery, evaluating their responses to light, vibration and settling in columns. The researchers also followed the motility of the animals over the recovery period (Sprecher et al. 2015). The functional assessment of brain activity was done in parallel with a careful analysis of nervous system anatomy by immunostaining, allowing the correlation of functional and structural aspects of the regeneration process. This study represents the first time that tests of this nature have been used to understand the physiological consequences of acoel regenerative processes (beyond the obvious characteristics like recovery of body movement). A striking finding of this study is that different sensory modalities are restored at different times. For instance, phototaxis is restored at about 20 days post-decapitation, while geotaxis takes approximately 50 days to be restored. The growing recognition that Symsagittifera roscoffensis is able to follow more complex behaviors (Franks et al. 2016) and even social behaviors offers further opportunities to study functional recovery in the nervous systems of these animals, once considered "simple". The use of automated tracking systems and computer simulation of individual and collective behaviors - as Franks and collaborators (2016) have done-will provide us with the necessary tools to analyze different aspects of the brain's functional recovery in detail.

\subsection{PRELIMINARY GENOMIC DATA}

The so-called post-genomic era has produced a flurry of papers addressing the characterization of many animal genomes and transcriptomes, information that allows us to trace the evolutionary history of animals with unprecedented detail. Among those animals for which new information has been gathered are several members of the phylum Xenacoelomorpha (an updated list appears in: Jondelius et al. 2019).

Three acoel genomes with different degrees of completeness have been produced in the last few yearsthose of species Hofstenia miamia (Gehrke et al. 2019), Praesagittifera naikaiensis (Arimoto et al. 2019) and Symsagittifera roscoffensis (Philippe et al. 2019). While the first is quite complete, that of our species is only a preliminary draft. Despite the relatively low quality of the Symsagittifera genome (a high-quality version is currently being generated), some basic facts can be extracted. The first is that the genome of Symsagittifera is quite big, around $1.4 \mathrm{~Gb}$, approximately half the size of the human genome. This is supported by an independent analysis of the genome size carried out by flow cytometry. This genome is much bigger than that of Hofstenia miamia, which has been reported to be $950 \mathrm{Mb}$ long, and Praesagittifera naikaiensis, which is estimated at $654 \mathrm{Mb}$. The genome of Symsagittifera is packed into 20 chromosomes of seemingly equal size $(2 n=20)$, as determined cytochemically using chromosomal spreads (Moreno et al. 2009).

Briefly, in the case of Symsagittifera roscoffensis, a standard fragment Illumina library was made from a pool of symbiont-free hatchlings, which were raised in artificial seawater in the presence of antibiotics. The genome fragments were assembled with a mix of SOAPdenovo2 (-M3, - R,$\mathrm{d} 1,-\mathrm{K} 31$ ) and the Celera assemblers, resulting in an N50 of 2,905 bp. The introduction of PacBio sequencing methodologies has recently allowed us to increase the N50 to above $100 \mathrm{~kb}$ (PM, unpublished data). Genome and transcriptome assemblies, including the genome of Symsagittifera, have been deposited in https://figshare.com/search, project number PRJNA517079. In parallel, a transcriptome was also sequenced from mixed-stage $S$. roscoffensis embryos using standard methods.

This is an A+T-rich genome with a $36 \%$ content of $\mathrm{G}+\mathrm{C}$ and a high representation of repetitive elements and transposons (data not shown). Some of the transposon sequences have been mapped to specific locations in the genome, such as the neighborhood of the Hox genes (Moreno et al. 2011), a particularity that would explain their dispersion in different chromosomes by rearrangements. The draft genome and the transcriptomes have allowed for the exploration of gene families and their compositions. Families such as those containing bHLH, GPCRs, Wnts or homeobox have been explored extensively in recent years (Perea-Atienza et al. 2015; Gavilán et al. 2016; Brauchle et al. 2018). Strikingly, many of these sequences show specific patterns of divergence with respect to the putative orthologs in other bilaterian clades (i.e. Wnts), corroborating the well-known fast rate of evolution of acoels, and in particular Symsagittifera, genomes (Philippe et al. 2019). Moreover, these gene family characterizations provide a source of sequences necessary for the design of probes used in downstream experiments by situ hybridization (Perea-Atienza et al. 2018) or in the identification of BAC 
clones used in studies of chromosomal mapping (Moreno et al. 2009).

\subsection{CHALLENGING QUESTIONS FOR THE FUTURE}

Some challenging questions need to be addressed in this model. The lack of functional tools has been a hindrance in the analysis of Symsagittifera biology from both a developmental and physiological perspective. Until now, we have relied on several molecular, anatomical and biochemical techniques to analyze aspects of the anatomy, embryology and metabolic activity of these animals under different conditions. This has provided us with an enormous body of knowledge, though mostly descriptive. The development of tools for knockdown and biochemical intervention (i.e. pharmacological agents) should be a priority in the field, so that phenomena discovered observationally can be tested directly through experimental intervention. Specifically, the following are needed:

1. A deeper understanding of the embryology of $S$. roscoffensis, including lineage maps and a dissection of blastomere contributions (through ablation methodologies). Furthermore, molecular markers should be incorporated into our understanding of embryonic regulation in $S$. roscoffensis.

2. We need a better understanding of how the $S$. roscoffensis genome is organized. This is necessary not only for the identification of key features of the genome (including intron/exon boundaries, synteny conservation, non-coding RNAs, indels, etc.) but also as an alternative tool for tackling the difficult problem of phylogenetic affinities. We believe that genomic characteristics can be of critical importance for phylogenomic reconstruction, beyond the "classical" use of primary sequence data.

3. A detailed characterization of cell types and their architectural organization in tissues is still missing in S. roscoffensis. High-throughput TEM reconstructions aided by single-cell transcriptomics would provide ample opportunities to understand how cell types are organized in $S$. roscoffensis and their putative enrichment in different subtypes. Combinations of single-cell data plus in situ hybridization will be necessary to reach this goal (spatial transcriptomics).

4. S. roscoffensis is a unique system for the study of symbiotic relationships. The host-algae interaction provides a rich metabolic partnership and is critical to the survival of animals in their environment. It is unknown how this symbiosis is achieved and controlled at the genetic level. The fact that both the host and the algae can be independently cultivated and mixed provides us with a unique opportunity to follow, in real time, the molecular activities involved in the symbiogenic process. The use of complementary techniques, such as TEM, can also aid our understanding of the morphological changes that take place in both partners during the symbiogenic process.

5. S. roscoffensis exhibits complex behavior at both the individual and collective levels. Factors such light, gravity or animal crowds elicit a clear behavioral response in $S$. roscoffensis. These diverse and rich behaviors observed in a relatively "simple" animal merit a deeper investigation. Genetic intervention-and, perhaps, neuronal ablationscould provide insight into the regulation of the $S$. roscoffensis behavioral repertoire.

6. Acoels show a remarkable capacity for regeneration of body parts. $S$. roscoffensis has been identified as an ideal system to study the regeneration of the head (and brain) from scratch. Understanding how this process occurs could be of great importance beyond the domain of fundamental biology. A combination of tools including gene mapping, gene editing or gene knockout approaches (such as CRISPR/CAS9) and single-cell sequencing could give us unprecedented access to the mechanisms that regulate nervous system reconstruction.

The implications of this work for biomedicine cannot be overstated.

The availability of some of the required technologies in related acoel species should prove especially relevant. Over the last years, we have seen the incorporation of RNAi methodologies in the study of the development of Isodiametra pulchra (De Mulder et al. 2009; Moreno et al. 2010) and Hofstenia miamia (Srivastava et al. 2014). Moreover, conventional techniques such as colorimetric and fluorescent multiplex in situ hybridizations plus immunochemical tools are now regular tools used in the analysis of the species of this chapter, S. roscoffensis, and have been described at extenso in the chapter published by Perea-Atienza and collaborators (Perea-Atienza et al. 2018; Perea-Atienza et al. 2020). To end this short overview, note that $S$. roscoffensis is the first acoel species in which behavioral tests have been devised (Nissen et al. 2015; Sprecher et al. 2015), opening the possibility of carrying out detailed analysis of the physiological role that tissues, cells and genes have in the Acoela.

\section{BIBLIOGRAPHY}

Achatz, J. G., Chiodin, M., Salvenmoser, W., Tyler, S., and Martinez, P. 2013. The Acoela: On their kind and kinships, especially with nemertodermatids and xenoturbellids (Bilateria incertae sedis). Org Divers Evol 13(2):267-286.

Apelt, G. 1969. Fortpflanzungsbiologie, Entwicklungszyklen und vergleichende Frühentwicklung acoeler Turbellarien. Marine Biol 8:267-325.

Arboleda, E., Hartenstein, V., Martinez, P., Reichert, H., Sen, S., Sprecher, S., and Bailly, X. 2018. An emerging system to study photosymbiosis, brain regeneration, chronobiology, and behavior: The marine acoel Symsagittifera roscoffensis. Bioessays 40:e1800107. 
Arimoto, A., Hikosaka-Katayama, T., Hikosaka, A., Tagawa, K., Inoue, T., Ueki, T., Yoshida, M. A., Kanda, M., Shoguchi, E., Hisata, K., and Satoh, N. 2019. A draft nuclear-genome assembly of the acoel flatworm Praesagittifera naikaiensis. GigaScience 8:giz023.

Bailly, X., Laguerre, L., Correc, G., Dupont, S., Kurth, T., Pfannkuchen, A., Entzeroth, R., Probert, I., Vinogradov, S., Lechauve, C., Garet-Delmas, M. J., Reichert, H., and Hartenstein, V. 2014. The chimerical and multifaceted marine acoel Symsagittifera roscoffensis: From photosymbiosis to brain regeneration. Front Microbiol 5:498.

Bedini, C., Ferrero, E., and Lanfranchi, A. 1973. The ultrastructure of ciliary sensory cells in two turbellaria acoela. Tissue and Cell 5:359-372.

Bedini, C., and Lanfranchi, A. 1991. The central and peripheral nervous system of Acoela (Plathelminthes): An electron microscopical study. Acta Zoologica 72:101-106.

Bery, A. E., Cardona, A., Martinez, P., and Hartenstein, V. 2010. Structure of the central nervous system of a juvenile acoel, Symsagittifera roscoffensis. Development Genes and Evolution 220:61-76.

Bely, A. E., and Sikes, J. M. 2010. Acoel and platyhelminth models for stem-cell research. J Biol 9:14.

Børve, A., and Hejnol, A. 2014. Development and juvenile anatomy of the nemertodermatid Meara stichopi (Bock) Westblad 1949 (Acoelomorpha). Front Zool 11:50.

Boyer, B. C. 1971. Regulative development in a spiralian embryo as shown by cell deletion experiments on the Acoel, Childia. J Exp Zool 176:97-105.

Boyer, B. C., Henry, J. Q., and Martindale, M. Q. 1996. Modified spiral cleavage: The duet cleavage pattern and early blastomere fates in the acoel turbellarian Neochildia fusca. Biol Bull 191:285-286.

Boyle, J. E., and Smith, D. C. 1975. Biochemical interactions between the symbionts of Convoluta roscoffensis. Proceedings of the Royal Society of London: Series B. Biological Sciences 189:121-135.

Brauchle, M., Bilican, A., Eyer, C., Bailly, X., Martínez, P., Ladurner, P., Bruggmann, R., and Sprecher, S. G. 2018. Xenacoelomorpha survey reveals that all 11 animal homeobox classes were present in the first bilaterians. Genome. Biol. Evol. 10:2205-2217.

Bresslau, E. 1909. Die Entwicklung der Acoelen. Verh Deutsch Zoologisch Gesell 19:314-323.

Brøndsted, H. V. 1955. Planarian regeneration. Biol Rev 30:65-126.

Child, C. M. 1907. The localisation of different methods of form-regulation in Polychoerus caudatus. Arch Entwm Org 23:227-248.

Delage, Y. 1886. Etudes histologiques sur les planaires rhabdocoeles acoeles (Convoluta schultzii O. Sch.). Arch Zool Exp Gen T4:109-144.

De Mulder, K., Kuales, G., Pfister, D., Willems, M., Egger, B., Salvenmoser, W., Thaler, M., Gorny, A. K., Hrouda, M., Borgonie, G., and Ladurner, P. 2009. Characterization of the stem cell system of the acoel Isodiametra pulchra. BMC Dev Bio 9:69.

Douglas, A. E. 1983a. Uric acid utilization in Platymonas convolutae and symbiotic Convoluta roscoffensis. J Mar Biol Ass UK 63:435-447.

Douglas, A. E. 1983b. Establishment of the symbiosis in Convoluta roscoffensis. J Mar Biol Ass UK 63:419-434.

Ehlers, U. 1985. Das phylogenetische System der Plathelminthes. Gustav Fischer Verlag, Stuttgart, New York.

Ehlers, U. 1991. Comparative morphology of statocysts in the Plathelminthes and the Xenoturbellida. Hydrobiologia 227:263-271.
Ehlers, U. 1992. Frontal glandular and sensory structures in Nemertoderma (Nemertodermatida) and Paratomella (Acoela): Ultrastructure and phylogenetic implications for the monophyly of the Euplathelminthes (Plathelminthes). Zoomorphology 112:227-236.

Ferrero, E. 1973. A fine structural analysis of the statocyst in Turbellaria acoela. Zoologica Scripta 2:5-16.

Franks, N. R., Worley, A., Grant, K. A., Gorman, A. R., Vizard, V., Plackett, H., Doran, C., Gamble, M. L., Stumpe, M. C., and Sendova-Franks, A. B. 2016. Social behaviour and collective motion in plant-animal worms. Proc Biol Sci 283.

Fuxe, K., Dahlström, A., Höistad, M., Marcellino, D., Jansson, A., Rivera, A., Diaz-Cabiale, Z., Jacobsen, K., Tinner-Staines, B., Hagman, B., Leo, G., Staines, W., Guidolin, D., Kehr, J., Genedani, S., Belluardo, N., and Agnati, L. F. 2007. From the Golgi-Cajal mapping to the transmitter-based characterization of the neuronal networks leading to two modes of brain communication: Wiring and volume transmission. Brain Res Rev 55:17-54.

Gamble, F. W., and Keeble, F. 1904. The bionomics of Convoluta roscoffensis, with special reference to its green cells. Proceedings of the Royal Society of London 72:93-98.

Gardiner, E. G. 1895. Early development of Polychoerus caudatus Mark. J Morphol 11:155-176.

Gavilán, B., Perea-Atienza, E., and Martinez, P. 2016. Xenacoelomorpha: A case of independent nervous system centralization? Philos Trans R Soc Lond B Biol Sci 371:1685.

Gavilán, B., Sprecher, S. G., Hartenstein, V., and Martinez, P. 2019. The digestive system of xenacoelomorphs. Cell Tissue Res 377:369-382.

Geddes, P. 1879. II: Observations on the physiology and histology of Convoluta schultzii. Proceedings of the Royal Society of London 28:449-457.

Gehrke, A. R., Neverett, E., Luo, Y. J., Brandt, A., Ricci, L., Hulett, R. E., Gompers, A., Ruby, J. G., Rokhsar, D. S., Reddien, P. W., and Srivastava, M. 2019. Acoel genome reveals the regulatory landscape of whole-body regeneration. Science 363.

Georgévitch, J. 1899. Etude sur le développement de la Convoluta roscoffensis Graff. Arch Zool Experim 3:343-361.

Gooday, G. W. 1970. A physiological comparison of the symbiotic alga Platymonas convolutae and its free-living relatives. $J$ Mar Biol Ass UK 50:199-208.

Graff, L. 1891. Sur l'organisation des turbellariés acoeles. Arch Zool Exp Gén T9:1-12.

Graff, L., and Haberlandt, G. 1891. Die Organisation der Turbellaria acoela; mit einem Anhange über den Bau und die Bedeutung der Chlorophyllzellen von Convoluta roscoffensis von Gottlieb Haberlandt. Engelmann, Leipzig.

Gschwentner, R., Ladurner, P., Nimeth, K., and Rieger, R. 2001. Stem cells in a basal bialterian: $\mathrm{S}$ phase and mitotic cells in Convolutriloba longifissura. Cell Tissue Res 304:401-408.

Hanson, E. D. 1960. Asexual reproduction in acoelous Turbellaria. Yale J Biol Med 33:107-111.

Hanson, E. D. 1967. Regeneration in acoelous flatworms: The role of the peripheral parenchyma. W. Roux' Archiv f. Entwicklungsmechanik 159:298-313.

Henry, J. Q., Martindale, M. Q., and Boyer, B. C. 2000. The unique developmental program of the acoel flatworm, Neochildia fusca. Dev Biol 220:285-295.

Hooge, M. D. 2001. Evolution of body-wall musculature in the platyhelminthes (Acoelomorpha, catenulida, rhabditophora). J Morphol 249:171-194.

Hori, I. 1997. Cytological approach to morphogenesis in the planarian blastema: The effect of neuropeptides. J Submicrosc Cytol Pathol 29:91-97. 
Hori, I. 1999. Cytological approach to morphogenesis in the planarian blastema: Ultrastructure and regeneration of the acoel turbellarian Convoluta naikaiensis. J Submicrosc Cytol Pathol 31:247-258.

Hulett, R. E., Potter, D., and Srivastava, M. 2020. Neural architecture and regeneration in the acoel Hofstenia miamia. Proc Biol Sci 287.

Hyman,L.H. 1951. Invertebrates: Platyhelminthes and Rhynchocoela, vol. 2. McGraw-Hill Inc., New York.

Jondelius, U., Raikova, O.I., and Martinez,P.2019. Xenacoelomorpha, a key group to understand bilaterian evolution: Morphological and molecular perspectives. In P. Pontarotti (Ed.), Evolution, Origin of Life, Concepts and Methods (pp. 287-315). Springer Nature.

Keeble, F. 1910. Plant-Animals: A Study in Symbiosis. Cambridge University Press, Cambridge.

Keeble, F., and Gamble, F. W. 1907. The origin and nature of the green cells of Convoluta roscoffensis. QJ Microsc. Sci 51:167-217.

Keil, E. 1929. Regeneration in Polychaerus caudatus Mark. Bio Bull 57:223-244.

Klauser, M. D., Smith, J. P. S., and Tyler, S. 1986. Ultrastructure of the frontal organ in Convoluta and Macrostomum spp.: Significance for models of the turbellarian archetype. Hydrobiologia 132:47-52.

Kiers, E. T., and West, S. A. 2016. Evolution: Welcome to symbiont prison. Current Biology 26:R66-R68.

Kostenko, A. G., and Mamkaev, Y. V. 1990. The position of green convoluts IN the system of acoel turbellarians (Turbellaria, Acoela). 2. Sagittiferidae fam. n. Zool. Zh. (Moscow) 69:5-16.

Ladurner, P., and Rieger, R. 2000. Embryonic muscle development of Convoluta pulchra (Turbellaria-acoelomorpha, platyhelminthes). Dev Biol 222:359-375.

Lowe, C. D., Minter, E. J., Cameron, D. D., and Brockhurst, M. A. 2016. Shining a light on exploitative host control in a photosynthetic endosymbiosis. Current Biology 26:207-211.

Lundin, K. 1997. Comparative ultrastructure of the epidermal ciliary rootlets and associated structures in species of the Nemertodermatida and Acoela (Plathelminthes). Zoomorphology 117:81-92.

Margulis, L. 1998. Symbiotic Planet: A New Look at Evolution, Kindle edition. Basic Books, New York.

Martinez, P., Hartenstein, V., and Sprecher, S. 2017. Xenacoelomorpha Nervous Systems. In S. Murray Sherman (Ed.), Oxford Research Encyclopedia of Neuroscience. Oxford University Press, New York.

Meyer, H., Provasoli, L., and Meyer, F. 1979. Lipid biosynthesis in the marine flatworm Convoluta roscoffensis and its algal symbiont Platymonas convoluta. Biochim Biophys Acta 573:464-480.

Moreno, E., De Mulder, K., Salvenmoser, W., Ladurner, P., and Martínez, P. 2010. Inferring the ancestral function of the posterior Hox gene within the Bilateria: Controlling the maintenance of reproductive structures, the musculature and the nervous system in the acoel flatworm Isodiametra pulchra. Evolution and Development 12:258-266.

Moreno, E., Nadal, M., Baguñá, J., and Martínez, P. 2009. The origin of the bilaterian Hox patterning system: Insights from the acoel flatworm Symsagittifera roscoffensis. Evolution and Development 11:574-581.

Moreno, E., Permanyer, J., and Martinez, P. 2011. The origin of patterning systems in bilateria-insights from the Hox and ParaHox genes in Acoelomorpha. Genomics, Proteomics and Bioinformatics 9:65-76.
Morris, P. J. 1993. The developmental role of the extracellular matrix suggests a monophyletic origin of the kingdom Animalia. Evolution 47:152-165.

Muscatine, L., Boyle, J. E., and Smith, D. C. 1974. Symbiosis of the acoel flatworm Convoluta roscoffensis with the alga Platymonas convolutae. Proceedings of the Royal Society of London: Series B. Biological Sciences 187:221-234.

Nissen, M., Shcherbakov, D., Heyer, A. G., Brümmer, F., and Schill, R. O. 2015. Behaviour of the platyhelminth Symsagittifera roscoffensis under different light conditions and the consequences for the symbiotic algae Tetraselmis convolutae. $J$ Exper Biol 218:1693-1698.

Nozawa, K., Taylor, D. L., and Provasoli, L. 1972. Respiration and photosynthesis in Convoluta roscoffensis Graff, infected with various symbionts. Biol Bull 143:420-430.

Oshman, J. 1966. Development of the symbiosis of Convoluta voscoffensis Graff and Platy-monas sp. J Phycol 2:111-116.

Parke, M., and Manton, I. 1967. The specific identity of the algal symbiont in Convoluta roscoffensis. J Mar Biol Ass UK 47:445-464.

Pedersen, K. J. 1965. Cytological and cytochemical observations on the mucous gland cells of an acoel turbellarian, Convoluta convulta. Ann NY Acad Sci 118:930-965.

Perea-Atienza, E., Botta, M., Salvenmoser, W., Gschwentner, R., Egger, B., Kristof, A., Martinez, P., and Achatz, J. G. 2013. Posterior regeneration in Isodiametra pulchra (Acoela, Acoelomorpha). Front Zool 10:64.

Perea-Atienza, E., Gavilan, B., Chiodin, M., Abril, J. F., Hoff, K. J., Poustka, A. J., and Martinez, P. 2015. The nervous system of Xenacoelomorpha: A genomic perspective. J. Exp. Biol. 218:618-628.

Perea-Atienza, E., Gavilán, B., Sprecher, S. G., and Martinez, P. 2020. Immunostaining and in situ hybridization of the developing acoel nervous system. In: S. Sprecher (Ed.), Brain Development: Methods in Molecular Biology, vol. 2047. Humana, New York, NY.

Perea-Atienza, E., Sprecher, S. G., and Martinez, P. 2018. Characterization of the bHLH family of transcriptional regulators in the acoel $S$. roscoffensis and their putative role in neurogenesis. EvoDevo 9:8.

Philippe, H., Brinkmann, H., Copley, R. R., Moroz, L. L., Nakano, H., Poustka, A. J., Wallberg, A., Peterson, K. J., and Telford, M. J. 2011. Acoelomorph flatworms are deuterostomes related to Xenoturbella. Nature 470:255-258.

Philippe, H., Poustka, A. J., Chiodin, M., Hoff, K. J., Dessimoz, C., Tomiczek, B., Schiffer, P. H., Müller, S., Domman, D., Horn, M., Kuhl, H., Timmermann, B., Satoh, N., HikosakaKatayama, T., Nakano, H., Rowe, M. L., Elphick, M. R., Thomas-Chollier, M., Hankeln, T., Mertes, F., Wallberg, A., Rast, J. P., Copley, R. R., Martinez, P., and Telford, M. J. 2019. Mitigating anticipated effects of systematic errors supports sister-group relationship between xenacoelomorpha and ambulacraria. Curr Biol 29:1818-1826.

Ramachandra, N. B., Gates, R. D., Ladurner, P., Jacobs, D. K., and Hartenstein, V. 2002. Embryonic development in the primitive bilaterian Neochildia fusca: Normal morphogenesis and isolation of POU genes Brn-1 and Brn-3. Development Genes and Evolution 212:55-69.

Raz, A. A., Srivastava, M., Salvamoser, R., and Reddien, P. W. 2017. Acoel regeneration mechanisms indicate an ancient role for muscle in regenerative patterning. Nat Commun 8:1260.

Reuter, M., Raikova, O. I., Jondelius, U., Gustafsson, M. K. S., Maule, A. G., and Halton, D. W. 2001. Organisation of the nervous system in the Acoela: An immunocytochemical study. Tissue and Cell 33:119-128. 
Rieger, R. M., Tyler, S., Smith, J. P. S., III, and Rieger, G. E. 1991. Platyhelminthes: Turbellaria. In F. W. Harrison and B. J. Bogitsh (Eds.), Microscopic Anatomy of Invertebrates, Vol. 3: Platyhelminthes and Nemertinea (pp. 7-140). WileyLiss, New York.

Sagan, L. 1967. On the origin of mitosing cells. Journal of Theoretical Biology 14:225-IN6.

Semmler, H., Bailly, X., and Wanninger, A. 2008. Myogenesis in the basal bilaterian Symsagittifera roscoffensis (Acoela). Front Zool 5:14.

Semmler, H., Chiodin, M., Bailly, X., Martinez, P., and Wanninger, A. 2010. Steps towards a centralized nervous system in basal bilaterians: Insights from neurogenesis of the acoel Symsagittifera roscoffensis. Dev Growth Differ 52(8):701-713.

Shinn, G. 1993. Formation of egg capsules by flatworms (Phylum platyhelminthes). Transactions of the American Microscopical Society 112:18-34.

Sikes, J. M., and Bely, A. E. 2010. Making heads from tails: Development of a reversed anterior-posterior axis during budding in an acoel. Dev Biol 338(1):86-97.

Smith, J., III, and Tyler, S. 1985. The acoel turbellarians: Kingpins of metazoan evolution or a specialized offshoot? In H. M. Conway, S. Morris, J. D. George, R. Gibson, and Platt (Eds.), The Origins and Relationships of Lower Invertebrates (p. 123142). Clarendon Press, Oxford.

Smith, J. P. S., and Tyler, S. 1986. Frontal organs in the Acoelomorpha (Turbellaria): Ultrastructure and phylogenetic significance. Hydrobiologia 132:71-78.

Smith, J. P. S., Tyler, S., Thomas, M. B., and Rieger, R. M. 1982. The morphology of turbellarian rhabdites: Phylogenetic implications. Trans Am Microsc Soc 101(3):209-228.
Sprecher, S. G., Bernardo-Garcia, F. J., van Giesen, L., Hartenstein, V., Reichert, H., Neves, R., Bailly, X., Martinez, P., and Brauchle, M. 2015. Functional brain regeneration in the acoel worm Symsagittifera roscoffensis. Biol Open 4:1688-1695.

Srivastava, M., Mazza-Curll, K. L., van Wolfswinkel, J. C., and Reddien, P. W. 2014. Whole-body acoel regeneration is controlled by Wnt and Bmp-Admp signaling. Curr Biol 24:1107-1113.

Steinböck, O. 1954. Regeneration azöler Turbellarien. Verb. Dtsch. Zool. Gesell., Tübingen, S. 86-94.

Stevens, N. M., and Boring, A. M. 1905. Regeneration in Polychœrus caudatus, Part I: Observations on living material. J. Experimental Zoology 2:335-346.

Todt, C. 2009. Structure and evolution of the pharynx simplex in acoel flatworms (Acoela). Journal of Morphology 270:271-290.

Todt, C., and Tyler, S. 2006. Ciliary receptors associated with the mouth and pharynx of Acoela (Acoelomorpha): A comparative ultrastructural study. Acta Zoologica 88:41-58.

Tyler, S., and Rieger, R. 1999. Functional morphology of musculature in the acoelomate worm, Convoluta pulchra (Platyhelminthes). Zoomorphology 119:127-141.

Yamasu, T. 1991. Fine structure and function of ocelli and sagittocysts of acoel flatworms. Hydrobiologia 227:273-282.

Yang, J., Liu, X., Yue, G., Adamian, M., Bulgakov, O., and Li, T. J. 2002. Rootletin, a novel coiled-coil protein, is a structural component of the ciliary rootlet. $J$ Cell Biol 159:431-440.

Zabotin, Y. I., and Golubev, A. I. 2014. Ultrastructure of oocytes and female copulatory organs of acoela. Biology Bulletin 41:722-735. 